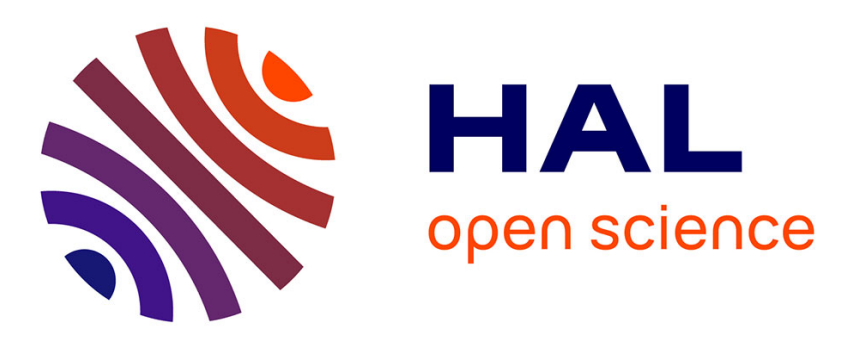

\title{
Touchdown bearing models for rotor-AMB systems
}

Clément Jarroux, Régis Dufour, Jarir Mahfoud, Benjamin Defoy, Thomas Ge Oil\&gas Thermodyn Alban, Adolfo Delgado

\section{To cite this version:}

Clément Jarroux, Régis Dufour, Jarir Mahfoud, Benjamin Defoy, Thomas Ge Oil\&gas Thermodyn Alban, et al.. Touchdown bearing models for rotor-AMB systems. Journal of Sound and Vibration, 2019, 440, pp.51-69. 10.1016/j.jsv.2018.09.058 . hal-01902817

\section{HAL Id: hal-01902817 https://hal.science/hal-01902817}

Submitted on 28 May 2019

HAL is a multi-disciplinary open access archive for the deposit and dissemination of scientific research documents, whether they are published or not. The documents may come from teaching and research institutions in France or abroad, or from public or private research centers.
L'archive ouverte pluridisciplinaire HAL, est destinée au dépôt et à la diffusion de documents scientifiques de niveau recherche, publiés ou non, émanant des établissements d'enseignement et de recherche français ou étrangers, des laboratoires publics ou privés. 


\title{
Touchdown bearing models for rotor-AMB systems
}

\author{
Clément Jarroux ${ }^{\mathrm{a}, \mathrm{b}}$, Régis Dufour ${ }^{\mathrm{a}, *}$, Jarir Mahfoud ${ }^{\mathrm{a}}$, Benjamin Defoy ${ }^{\mathrm{b}}$, \\ Thomas Alban ${ }^{\mathrm{b}}$, Adolfo Delgado ${ }^{\mathrm{c}}$ \\ ${ }^{a}$ Univ Lyon, INSA-Lyon, CNRS UMR5259, LaMCoS, F-69621, France \\ ${ }^{b}$ GE Oil and Gas, 480 Avenue Gustave Eiffel, 71200 Le Creusot, France \\ ${ }^{c}$ GE Global Research Center, 1 Research Circle, Niskayuna, NY 12309, USA
}

\begin{abstract}
This paper investigates numerically and experimentally the rotor drop dynamics when unexpected Active Magnetic Bearings (AMBs) shut down occurs. In such an event, the rotor behaviour drops on two touchdown bearings (TDBs) composed of a ball bearing and a ribbon damper providing stiffness and damping to the overall system. The aim of this paper is to establish and to validate the rotor-drop system model. A first experimental set up is used to identify the dynamic characteristics of the corrugated ribbon damper and to test the Kelvin-Voigt model and the generalized Dahl model. Then, three TDB models are proposed including either the first or the second ribbon damper models. The second experimental set-up is devoted to the rotor drop response of an industrial scale rotor-AMB system equipped with two TDBs. Rotor drop simulations in the time domain are carried out by using the Finite Element method and the three TDB models. Predicted and measured rotor drop responses are compared regarding the displacements as well as transmitted loads and permits evaluating the model efficiency.
\end{abstract}

Keywords: Active Magnetic Bearing, Touchdown bearing, Ribbon damper, Dry friction, Rotor drop dynamics

\footnotetext{
${ }^{*}$ Corresponding author

Email address: regis.dufour@insa-lyon.fr (Régis Dufour)
} 


\section{Introduction}

Active Magnetic Bearings (AMBs) are widely used in different industrial applications and have been successfully implemented in the field of turbomachinery. This technology provides the means for frictionless rotor support by 5 using magnetic levitation, see Schweitzer and Maslen [1] for more details. The forces generated are unstable by nature and a control loop, typically an augmented PID controller, is required to avoid instabilities. In some particular events, AMBs can shut down and the rotor drops onto its touchdown bearings (TDBs), often ball bearings, providing a back-up support. Since the restor-

10 ing forces of the AMB no longer present during rotor drop events, the normal critical velocity in the sense of Bartha [2] should be nil, enabling in theory, backward whirl behaviours. There are two types of drops: vertical drop (vertical machines: rotor axis is parallel to the direction of the gravity) and horizontal drop. Vertically dropped rotors were studied in references $[3,4,5,6,7]$. The gravity does not lead to stable motion and the rotor is more able to develop a forward whirl motion, as explained by Wilkes et al. [8]. The forward whirl motion is frequency-limited and this is consistent with many of the previous studies concerning the rotor-stator interaction, see references $[9,10,11,12,13]$.

In this paper, only horizontal assembly are considered. During drop, gravity tends to stabilize the rotor at the bottom of its TDBs, compensating for the loss of the bearing restoring forces. Gravity counteracts the friction forces generated by the contact. Generally speaking, and according to experimental results, pendulum oscillations of the rotor set-up just after it rebounds, as shown in references $[14,15]$. In some cases, such as, high friction coefficient, stiff support,

25 very low damping or misalignment, see Keogh and Cole [16] or Halminen et al. [17], the rotor may develop backward whirl affecting the integrity of the machine. On this particular aspect, Maslen et al. [18] analytically predicted the feasibility of a backward whirl motion, called U-shaped plot, depending on the deviation from a nominal friction coefficient and the damping present in the TDB. Many studies pointed out the need for a well-balanced rotor during 
coast-down, see references $[19,20]$. It is shown that passing through the first bending mode during a rotor drop followed by a coast-down may be an issue even if Siegl et al. [21] showed that no dangerous behaviours were triggered. The nonlinear dynamic regimes associated with rotor coast-down were analysed in references $[22,23]$. Jumps, periodic, quasi-periodic and chaotic motions may be found. Generally, high stiffness support combined with a low support damping and high unbalance mass levels are prone to generate multi-frequency responses and chaotic motions. The effects of the dynamic parameters of the support have a fundamental influence on rotor drop dynamics, as analysed in references [24, $25,26]$. Reducing the stiffness of the TDB support may improve the dynamic system response, but there is a trade-off between reducing impact forces and whirl frequencies, and maximum rotor excursion given by seal clearances. In this context, Siebkea et al. [27] proposed a new bushing-type TDB design to provide vertical flexibility.

There are various TDB models available depending on the need of the study and their modellings are still the subject of intensive research. Bearings manufacturers may need detailed models where interactions between races and each rolling elements are considered; it permits the estimation of the TDB life time for example. This is the case in references $[4,21,28,29]$ where the main objective for the TDB modelling focuses on the rolling elements. Helfert et al. [30] analysed with a rapid camera the rotation of the balls of a cageless TDB during a rotor drop. They observed that the balls as well as the inner race reached the shaft rotational speed almost at the same time: the sliding between the rolling elements do not significantly influence the time needed for the TDB to reach the rotor spin speed. As explained by Kärkkäinen et al. [20], considering the prediction of the overall dynamic behaviour of turbomachinery, such a detailed model, where each rolling element has several degrees of freedom, seems not to be necessary. Moreover, Sun et al. [4] emphasized that if well assessed, the required axial preload avoids the radial stiffness decrease of angular contact ball bearing with respect to rotational speed. In the light of these conclusions, the modelling of each rolling elements seems to be irrelevant for the targeted appli- 
cation in this study since the focus is on the overall dynamic response of the rotor.

Typically, TDB outer races are installed in series with compliant devices limiting the loads transmitted to the stator and providing damping to the overall system. In this study, a corrugated steel foil denominated ribbon damper is used as the compliant device. The latter is a key parameter for rotor drop dynamics, as shown by Jarroux et al. [31]. Most studies done on rotor drop dynamics consider the ribbon as a classical Kelvin-Voigt model. Wilkes et al. [8] used a cross-coupled stiffness coefficient that counteracts whirl motion depending on the sign of the outer race whirl speed. However, dynamic characterization tests of the ribbon, presented in this work, have shown the damping would be related to dry friction rather than viscous damping. Dry friction is a well-known phenomenon which is often used to reduce vibrations of mechanical structures; see for example the devices integrated under turbojet engine platforms (fan blade supports) presented by Ciğeroğlu et al. [32]. Macroslip and microslip models are the two main types of friction models and the choice between these may be important, as explained by Chatelet et al. [33]. Considering macroslip models, the dynamic behaviour is homogeneous, meaning that every contact slips or sticks at the same time while in microslip, mixed configurations appear. In the case of multiple contacts, the stick-slip transition can be either in the same time, allowing the use of macroslip models or during an interval of time, allowing the use of microslip models. Regardless of the selected model, dry friction is responsible for the peak flattening in frequency responses, as shown by Michon et al. [34]. Depending on the proportion of stick and slip, one can find optimum parameters to obtain the smallest peak at resonance. Two main approaches are employed to explain this peak flattening. Energy-based approaches state that this nonlinear behaviour is related to the energy dissipated in hysteresis loops; the larger the area the more energy is dissipated, therefore, the more the resonant peak is flattened. On the other hand, this could be explained by the change of the boundary conditions generated by friction. More precisely, the phase shift between the friction force and the displacement would be the cause 
of this peak flattening, conclusion of Al Sayed et al. [35].

There is a clear interest, in terms of operability, conception and safety of 95 turbomachinery, in studying and predicting accurately the dynamic behaviour and loads generated when a rotor drops onto its TDBs. The first part of this paper describes the newly developed ribbon model based on the dry friction theory and benchmarked to experimental results. Following this description, three TDB models are used to predict the rotor support dynamic response after the AMBs shut down. The first one is a bilinear contact law, based on Schmied and Pradetto [3] and used as reference. The two others consider 2 DOF per race, as used by Sun et al. [5] or Wilkes et al. [8]. One of them includes the newly developed ribbon damper model. The models tested also consider the rotational dynamics of the ball bearings. Finally, drop simulations at rest and at a giving rotational speed are then performed with these models. Numerical results are compared with rotor drop experimental results on an industrial scale test rig. The aim of this paper is to determine the most adequate TDB model to be used in rotor drop dynamics simulations when focusing on the overall rotor response.

\section{Ribbon damper characterisation}

\subsection{About ribbon dampers}

Sun et al. [5] presented drop simulations for a TDB supported on squeeze film dampers, which are commonly used in the aerospace industry and can minimize relative rotor-support motions. However, these devices require a lubrication system and, to some extent, defeat the purpose and advantages of using AMB technology. Ribbon dampers, made of a corrugated steel foil, represent an alternative oil-free device capable of dissipating energy that has been widely adopted in modern TDB designs, see Figure 1(a). These devices are fitted between the TDB outer race and the housing, as shown in Figure 1(b).

The ribbon damper is a key element when modelling rotor drop dynamics as shown by Jarroux et al. [31]. For this reason, component-level dynamic 


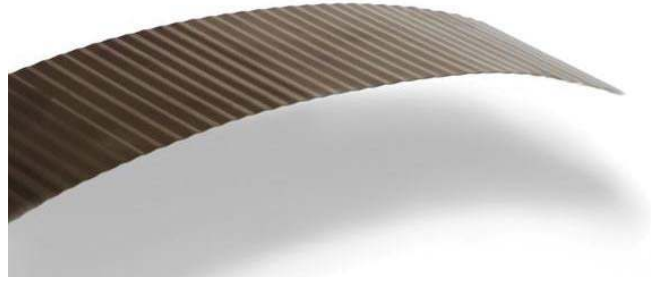

(a) Picture of a corrugated steel ribbon

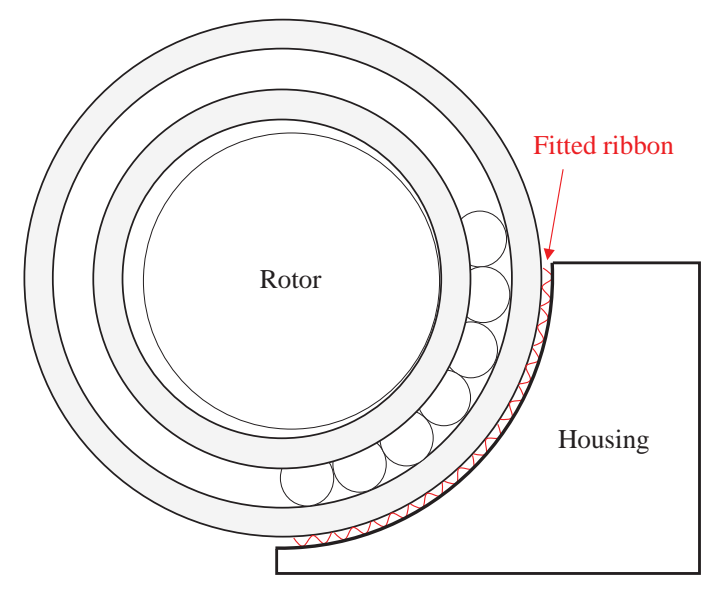

(b) Scheme of a TDB-housing assembly

Figure 1: TDB with a corrugated ribbon damper

characterization tests were carried out. The corrugated foil bumps contact the outer race of the ball bearing at multiple points making it difficult to model its dynamic response. The selected approach focuses on the restoring force extracted from experimental force-deflection loops. Complex foil models have been developed by Le Lez et al. [36] for characterizing dynamic performance of the corrugated foil in gas foil bearings, which resembles the geometry of corrugated ribbon dampers. Elementary stiffness matrices are obtained and a complete mesh describes finely the bumps deflections and displacements. Dry friction is considered in contact points. More detailed information concerning analytical methods or experimentations is given in Iordanoff et al. [37], BouSaid et al. [38], and Balducchi et al. [39], Andrés et al. [40], respectively.

The aim of the component-level tests is to extract the ribbon restoring force when subjected to harmonic excitations with different forcing amplitudes and frequencies. Figure 2 depicts the component-level test rig developed for characterizing the damper ribbon dynamic performance while subjected to similar operating conditions as those expected in the industrial scale system-level test rig.

Two $8900 \mathrm{~N}$ electro-hydraulic shakers, fixed to a bedplate, impose harmonic force excitation to the mandrel via two brackets, as shown in Figure 2. 


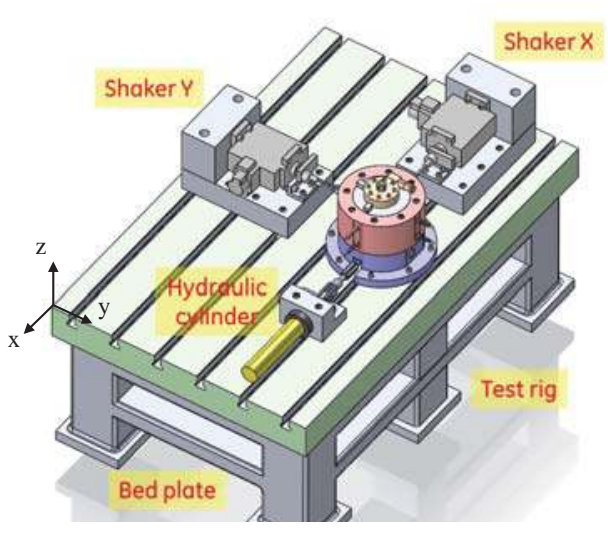

(a) Test rig frame

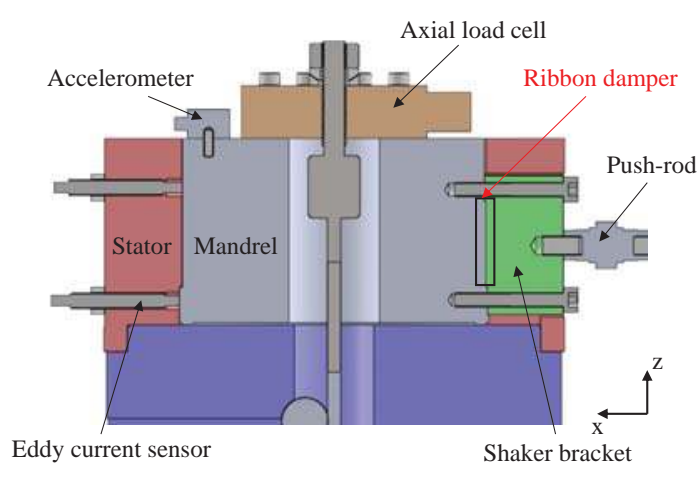

(b) Mandrel housing

Figure 2: Ribbon test rig

The wrapped ribbon damper is fitted between the mandrel and the stator; it is only deflected by the mandrel. Two piezoelectric cells connected to push-rods record the forces transmitted to the mandrel while two eddy current sensors (bottom and top) placed into the stator measure the relative displacement of the mandrel. A triaxial accelerometer bolted atop the mandrel provides acceleration measurements. The ribbon force response is identified by subtracting the inertia force to the measured external force, assuming that the ribbon is only subject to these two forces. The sampling frequency is $8192 \mathrm{~Hz}$ and the tests are harmonic and unidirectional for different imposed displacements and frequencies. The following sections present a description of the ribbon damper experimental results and numerical models.

\subsection{Dry friction phenomena}

A test matrix including 29 independent tests was carried out at different frequencies for several imposed sinusoidal displacements. For each of these test cases, the signals are recorded during $0.5 \mathrm{~s}$ once the steady-state motion is reached. Let $f_{\text {rd }}$ the ribbon restoring force and $u$ the mandrel displacement. Figure 3 presents the force-deflection loops for the $20 \mathrm{~Hz}$ test case normalized with $f_{\mathrm{rd}_{\max }}$ and $u_{\max }$ which are the maximal values reached during the quasistatic test plotted in Fig. 5. 


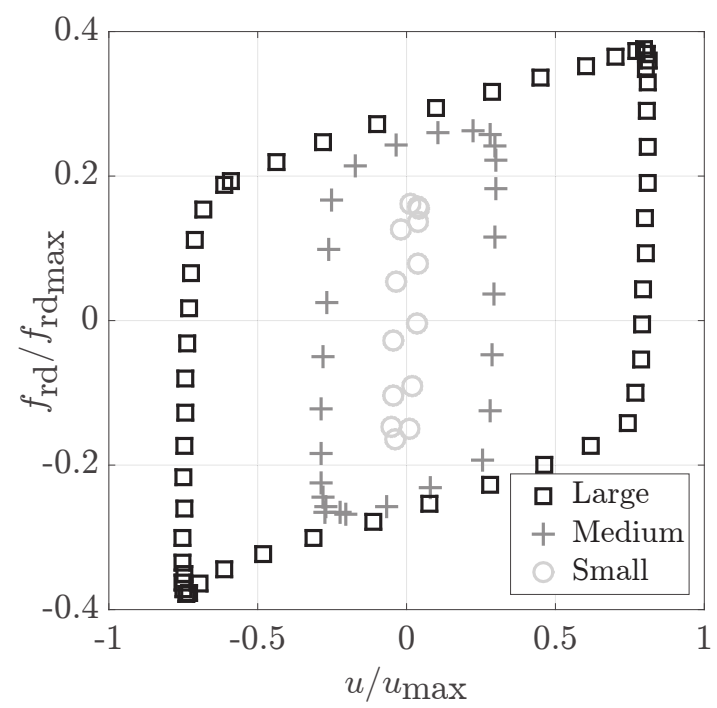

Figure 3: Normalized ribbon force-deflection loops measured for small, medium and large displacements imposed by the mandrel

The force-deflection loop is hysteretic and quasi-symmetric regarding the zero origin, denoting that the compression and traction phases are rather similar. The angular corners at the change of the velocity sign confirm a dry friction behaviour inducing a stick-slip phenomenon. Since the ribbon multiple contacts provide dry friction, the behaviour does not depend on the forcing frequency. The force-deflection loop exhibits a hysteretic behaviour with two slopes changes.

As the mandrel starts moving and deflecting the ribbon, see Figure 4(a), there is initially no relative motion at the contact points between the ribbon, the mandrel and stator due to dry friction. During this stick regime the ribbon yields global large stiffness, known as contact stiffness, see Figure 4(b). As the ribbon restoring force increases, the slipping threshold force $\mu F_{\mathrm{N}}\left(F_{\mathrm{N}}\right.$ being the normal contact force and $\mu$ the friction coefficient) is reached. All of these bumps slip, see Figure 4(c), resulting in a global smaller stiffness, known as residual stiffness or slipping stiffness, see Figure 4(d).

The damping provided by the ribbon when a rotor drops onto its TDBs comes mainly from the stick-slip alternating states of each ribbon bump, rubbing along the outer race and housing surfaces. 


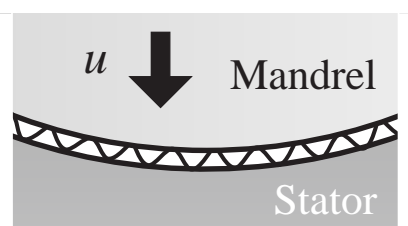

(a) Stuck bumps

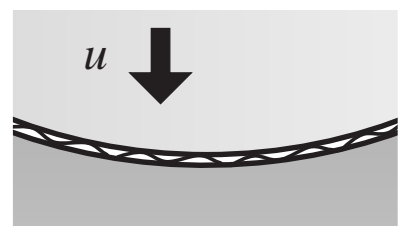

(c) Slipping bumps

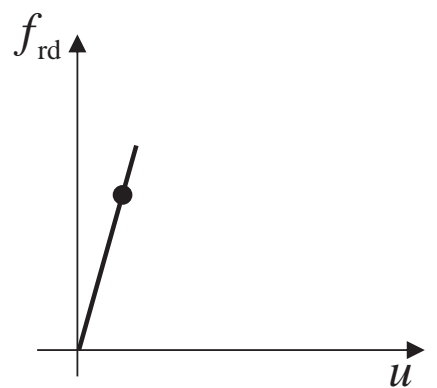

(b) Ribbon restoring force with stuck bumps

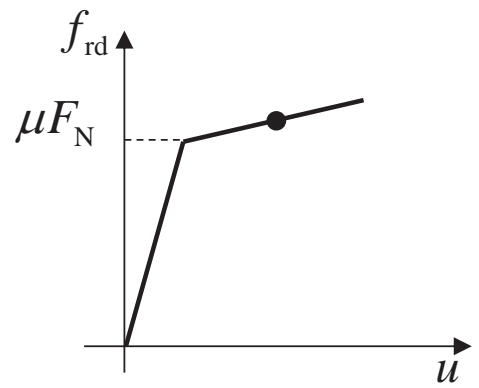

(d) Ribbon restoring force with slipping bumps

Figure 4: Stick-slip phenomenon due to the ribbon damper

\subsection{Models and results}

The aim of this subsection is to assess the capability of two damper models to reproduce the previously observed phenomena, namely, the generalized Dahl and the Kelvin-Voigt models. The latter is used here as reference for comparison purposes since it is usually employed in rotor drop dynamics investigations such as in references $[4,17,20,29]$.

\subsubsection{The generalized Dahl model}

The Dahl model, generalized by Al Majid and Dufour [41, 42] is based on a nonlinear first order differential equation, given in Eq. (1). Any shape of force-deflection can be adopted in order to model the ribbon restoring force $f_{\text {rd }}$.

$$
\frac{\mathrm{d} f_{\mathrm{rd}}}{\mathrm{d} t}=\beta \frac{\mathrm{d} u}{\mathrm{~d} t}\left(h-f_{\mathrm{rd}} \operatorname{sgn}\left(\frac{\mathrm{d} u}{\mathrm{~d} t}\right)\right)
$$




$$
h=\frac{1}{2}\left(h_{\mathrm{u}}+h_{\mathrm{l}}+\left(h_{\mathrm{u}}-h_{\mathrm{l}}\right) \operatorname{sgn}\left(\frac{\mathrm{d} u}{\mathrm{~d} t}\right)\right)
$$

The $\beta$ term is the only parameter that controls the transition between slip and stick states. Implementing a high value of $\beta$ leads to a mainly macroslip behaviour. The envelop $h$ depends on the sign of the deflection velocity to become either $h_{\mathrm{u}}$ or $h_{1}$, which are respectively the upper and the lower asymptotic envelops of the measured hysteretic loop plotted in Figure 5.

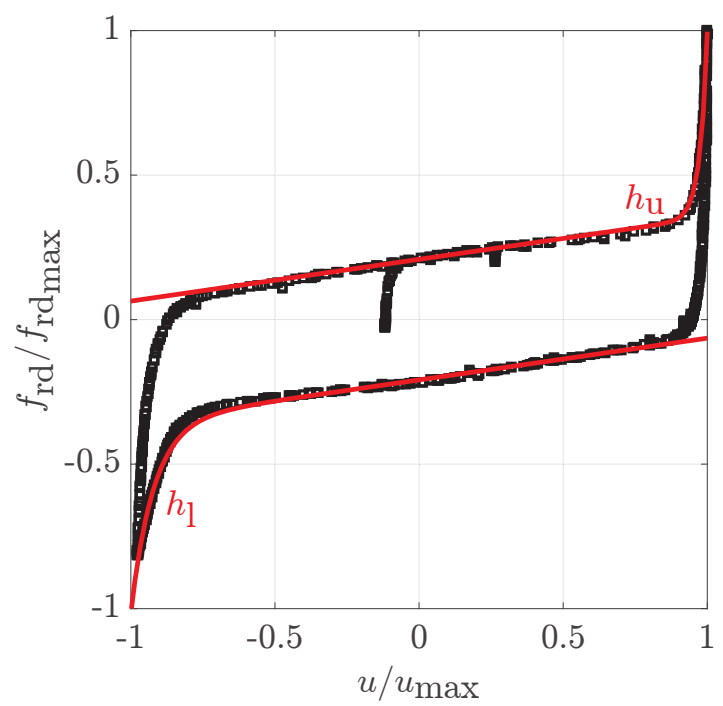

Figure 5: Normalized ribbon quasi-static force-deflection loop measured (dotted line) and the upper $h_{\mathrm{u}}$ - lower $h_{1}$ envelops (solid lines)

$$
\left\{\begin{array}{l}
h_{\mathrm{u}}=\mu F_{\mathrm{N}}+k_{\mathrm{slip}} u+a \mathrm{e}^{b u} \\
h_{\mathrm{l}}=-\mu F_{\mathrm{N}}+k_{\mathrm{slip}} u-c \mathrm{e}^{-d u}
\end{array}\right.
$$

As these envelops are curved fitted, see Eq. (3), the hysteretic behaviour is characterized by a force-deflection relationship where $\mu F_{\mathrm{N}}$ is the slipping threshold and $k_{\text {slip }}$ is the slipping stiffness (residual stiffness). Due to the double stopped-ends (actually the mandrel and stator), the ribbon exhibits a hardeninghardening nonlinear behaviour for the higher deflections and $a, b, c, d$ are the exponential parameters of the envelop curves. The main assumption lies in the fact that the dynamic behaviour of the ribbon when subjected to harmonic or transient loads is assumed to be identical. Indeed, the data used for the set-up 
of the generalized Dahl model comes from harmonic tests while the application targeted concerns rotor drop and transient dynamics. However, this assumption seems to be reasonable according to previous experiences conducted by Al Majid and Dufour [41].

\subsubsection{The Kelvin-Voigt model}

Eq. (4) describes the so-called Kelvin-Voigt model, which is representative of a spring-damper system and commonly used in rotor drop dynamic simulations. This model is characterized by its stiffness and damping, but also by its "crushing capacity"; the larger the crushing, the larger the provided damping. When the latter is flattened, the outer race reaches the housing and the TDB faces higher loads. The stiffness $k_{\mathrm{rd}}$ is provided by the manufacturer and the damping $c_{\mathrm{rd}}$, measured with logarithmic decrement technique, is set to 0.16.

$$
f_{\mathrm{rd}}=c_{\mathrm{rd}} \frac{\mathrm{d} u}{\mathrm{~d} t}+k_{\mathrm{rd}} u
$$

Sometimes a cross-coupled stiffness term opposed to the outer race whirling motion is applied to counteract rotor whirl, see references $[7,8]$.

\subsubsection{Results}

The displacements measured with the eddy-current sensors and their time derivatives are the input for the two developed models described by Eq. (1) and (4).

Figure 6 compares the force-deflection loops simulated and measured with a $20 \mathrm{~Hz}$ forcing frequency. The generalized Dahl model, see Figure 6(a), is accurate enough for all ranges of imposed displacement whether the stiffness parameter $\beta$ is well assessed. On the other hand, the Kelvin-Voigt model using manufacturer parameters, see Figure 6(b), represents the slip stiffness without considering any stick-slip phenomenon. Even if the amount of damping is related to the phase shift generated by stick-slip phenomenon rather than the dissipated energy, the area of hysteretic loop remains a good indicator for the purpose of this work. The Kelvin-Voigt model seems to significantly underpredict damping. 


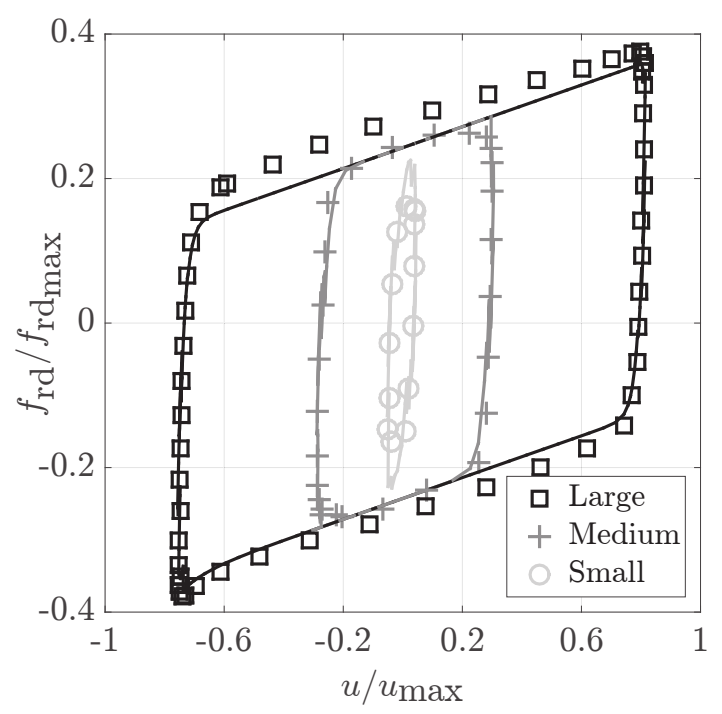

(a) Generalized Dahl model

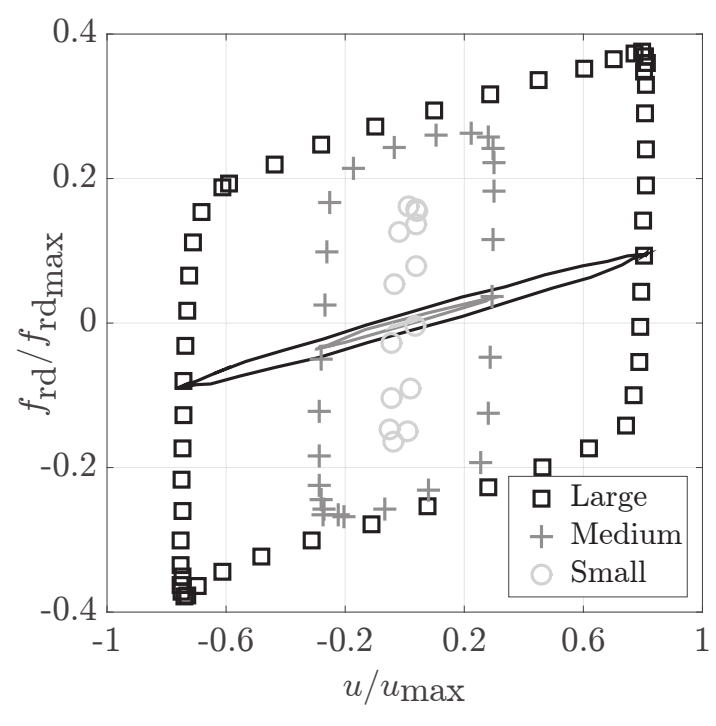

(b) Kelvin-Voigt model

Figure 6: Normalized ribbon force-deflection loops measured (dotted lines) and simulated (solid lines) for small, medium and large displacements imposed by the mandrel

These two models are implemented independently in the TDB model described in the Section 4.

\section{Ball bearing modelling}

The ball bearing, sketched in Figure 7(a), can be modelled by a radial forcedeflection relationship which may come from experimental, finite element or analytical results. The latter is employed in this study for its simplicity and efficiency. The rotational modelling is also considered.

\subsection{Dynamic parameters}

The literature related to ball bearing dynamic modelling is extensive and the most relevant references to this work are given by $[43,44,45,46]$. Recently, Guay [47] summarized the procedure to set-up the load-deflection relationship of a ball bearing, based on geometrical and material characteristics. Generally speaking, this procedure requires:

1. The bearing geometric parameters such as radii of elements in contact, materials, type of contact etc. Equivalent radii and curvature differences 


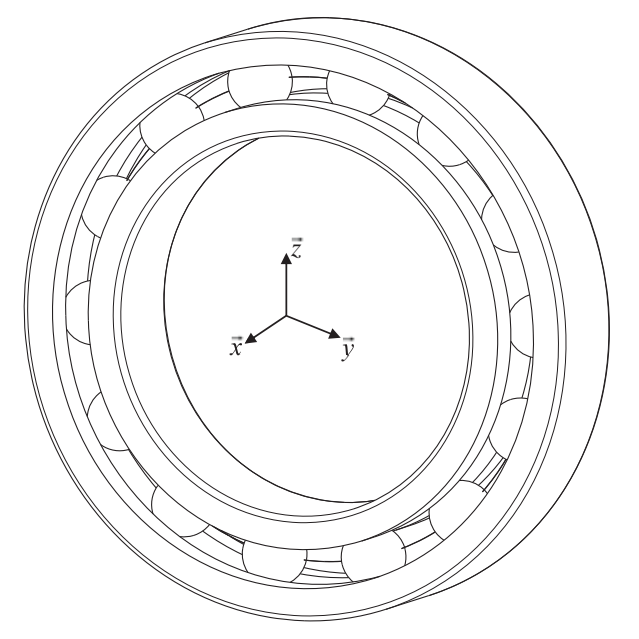

(a) Scheme of a deep groove ball bearing

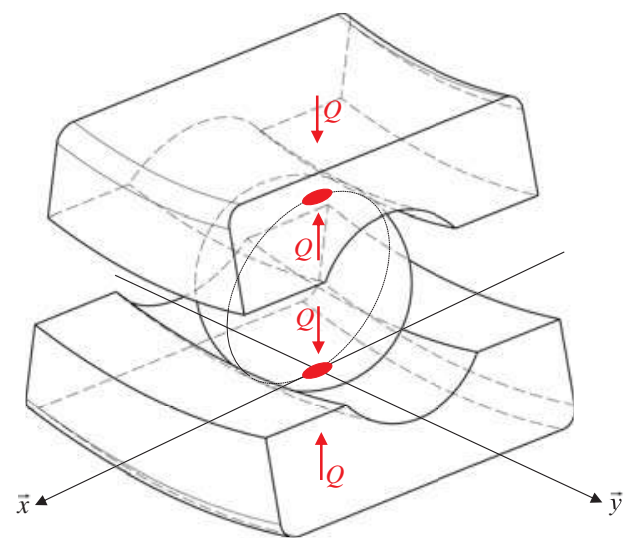

(b) One rolling element contact case

Figure 7: Loaded ball bearing

can be set-up to describe the races rolling-elements interactions.

2. The derivation of the contact stress and the approximation of elliptic integrals to obtain the load-deflection relationship for one rolling element in contact with both the inner and outer races, loaded by the force $Q$, see Fig. 7(b).

3. Take into consideration the bearing static equilibrium when subjected to an external load in order to determine the global load-deflection relationship.

This procedure is briefly described hereafter and readers can refer to Harris [45] or Guay [47] for more informations.

Assuming that the outer race is clamped, the static equilibrium gives the relationship between external axial $F_{\mathrm{a}}$ and radial $F_{\mathrm{r}}$ loads and the overall radial deflection $u_{\mathrm{r}}$ of the ball bearing, see Eq. (5).

$$
\begin{aligned}
& F_{\mathrm{a}}=\frac{Z k_{\mathrm{n}}}{2 \pi} \sin \alpha_{\mathrm{c}}\left(2 \epsilon u_{\mathrm{r}} \cos \alpha_{\mathrm{c}}\right)^{\frac{3}{2}} \int_{-\vartheta_{0}}^{+\vartheta_{0}}\left(1-\frac{1}{2 \epsilon}(1-\cos \vartheta)\right)^{\frac{3}{2}} d \vartheta \\
& F_{\mathrm{r}}=\frac{Z k_{\mathrm{n}}}{2 \pi} \cos \alpha_{\mathrm{c}}\left(2 \epsilon u_{\mathrm{r}} \cos \alpha_{\mathrm{c}}\right)^{\frac{3}{2}} \int_{-\vartheta_{0}}^{+\vartheta_{0}}\left(1-\frac{1}{2 \epsilon}(1-\cos \vartheta)\right)^{\frac{3}{2}} \cos \vartheta d \vartheta
\end{aligned}
$$


with $u_{\mathrm{r}}$, the radial deflection, $Z$, the total number of balls, $\vartheta$, the azimuth angle, $\alpha_{\mathrm{c}}$, the bearing contact angle and $\epsilon$, the load distribution factor. The coupled normal stiffness $k_{\mathrm{n}}$ is defined in Eq. 6 , as the sum of the inner $k_{\text {ir }}$ and outer $k_{\text {or }}$ race / rolling element contact stiffnesses in series mode, defined in Eq. 7 , where the subscript $\mathrm{j}$ represents either the inner ir and the outer or races.

$$
\begin{gathered}
k_{\mathrm{n}}=\left(\frac{1}{k_{\mathrm{ir}}^{\frac{2}{3}}}+\frac{1}{k_{\mathrm{or}}^{\frac{2}{3}}}\right)^{-\frac{3}{2}} \\
k_{\mathrm{j}}=\frac{\pi \kappa_{\mathrm{j}} E}{3}\left[\frac{2 S_{\mathrm{j}}\left(\kappa_{\mathrm{j}}\right) \Re_{\mathrm{j}}}{F_{\mathrm{j}}\left(\kappa_{\mathrm{j}}\right)^{3}}\right]^{\frac{1}{2}}
\end{gathered}
$$

where $\Re_{\mathrm{j}}$ is the equivalent radius, $\kappa_{\mathrm{j}}$ is the ellipticity parameter, $E$ is the equivalent Young modulus, $F_{\mathrm{j}}(\kappa)$ and $S_{\mathrm{j}}(\kappa)$ are the elliptic integrals of the first and second kinds respectively.

This analytical method is used and compared with the FE method: a mesh where balls and races are modelled with 3D elements was created. The outer race was clamped and a distributed radial load was applied on the inner race surface. The relative inner-outer race radial deflection was recorded. This was done for the case of a double-row angular contact ball bearing with races made of nitrogen steel and ceramic balls. The results are reported in Figure 8.

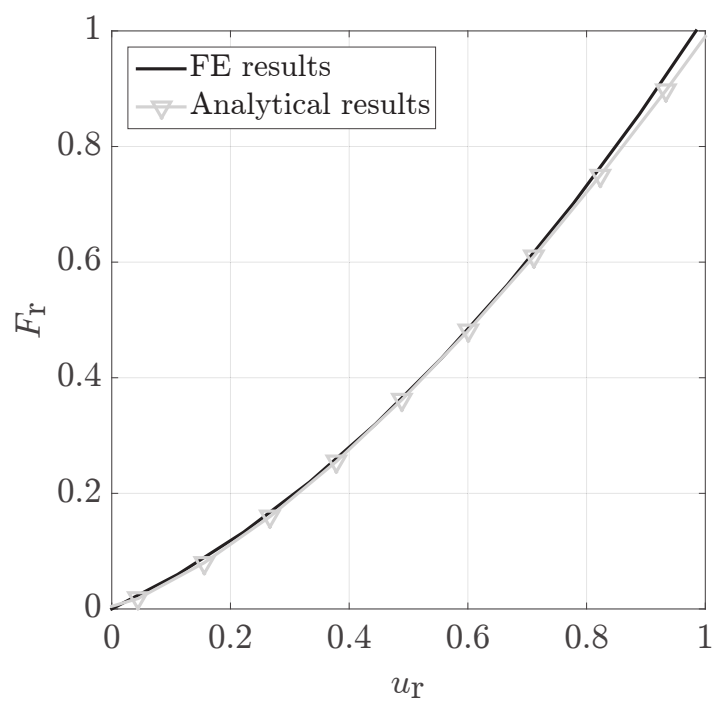

Figure 8: Normalized force-deflection - comparison between the FE and the selected analytical methods 
It appears that the analytical and the FE methods provide close results. The linearisation is performed by deriving the force-deflection relationship $F_{\mathrm{r}}$ of the bearing around an operating point to obtain conventional stiffness $k_{\text {brg }}$ parameter.

Damping in a ball bearing is rather small and complex to determine. According to Dietl et al. [48], the main sources of damping in a ball bearing are due to lubricant, Hertzian hysteresis due to rolling deformations and friction between the outer race and the support. For the application targeted, no lubri-

where $k_{\text {brg }}$ is the linearised stiffness value of the ball bearing. As the bearing damping is very small, this raw estimation is adequate for the present model.

\subsection{Rotational dynamics}

The spin-up is one of the key feature of the ball bearing type TDB. The employed method consists in calculating an equivalent rotational inertia of the TDB by taking into account the different kinetic energy contributions of each bearing component, as in references [20, 28]. The main advantage of this modelling is its simplicity of resolution since it is represented by only one equation of motion. The major uncertainties lie in the assumptions made about the kinematic conditions of the bearing elements and in the internal resistance torque modelling used. The equation of motion is given in Eq. (9).

$$
I_{\mathrm{eq}} \dot{\Omega}_{\mathrm{tdb}}+\Phi \Omega_{\mathrm{tdb}}=f_{\mathrm{t}} R_{\mathrm{ir}}-M_{1}
$$

with $R_{\text {ir }}$, the inner race radius, $f_{\mathrm{t}}$, the driven friction force produced by rotor inner race interactions and $\Omega_{\mathrm{tdb}}$, the TDB speed of rotation. The equivalent rotational inertia $I_{\text {eq }}$ takes into account the inner race and balls. Assuming 
a perfect rolling-without-slipping kinematic condition, $I_{\mathrm{eq}}$ may be established. The internal resistance torque in a ball bearing is generated by various and complex physical phenomena. Most of the analytical models have been developed empirically based on these operating conditions. According to Palmgren, the global resistance torque $M$ is the sum of $M_{1}$, due to external forces, $M_{2}$ due to the lubricant and $M_{3}$ due to seal frictions. In case of rotor drop, the bearing must face transient loads and high accelerations. Such conditions differ completely from those experienced in conventional ball bearing operations. However, the semi-empirical models are often used for rotor drop analysis due to a lack of knowledge. As the TDB design considered in this research work has no lubricant nor seals, $M_{2}$ and $M_{3}$ torques are not considered. Only the resistance torque $M_{1}$ due to external loads is considered. The detailed formulations of these torques are provided by Harris [45]. Alternative rotor-TDB contact and non-contact situations may be found while the resistance torque $M_{1}$ appears only when an external load is applied to the bearing. This means that no resistance torque is able to decelerate the ball bearing without any external load. To this end, a rotational damping coefficient $\Phi$ is added to the bearing system as previously done in references $[22,26]$.

The ball bearing modelling has been completely described. It consists of a radial force-deflection relationship based on well-known analytical works. The rotational dynamics is considered with a single equation of motion using an equivalent rotational inertia and a resistance torque.

\section{Touchdown bearing models}

The TDB models consider the ribbon damper and the ball bearing. They are modelled either with a contact law, based on the work of Schmied and Pradetto [3], see Figure 9(a), or with a 4-DOF model, see Figure 9(b).

These models are selected for two specific reasons:

1. Determining the degree of detail required for TDB models to represent (with sufficient accuracy) the system rotordynamic during drop events. 


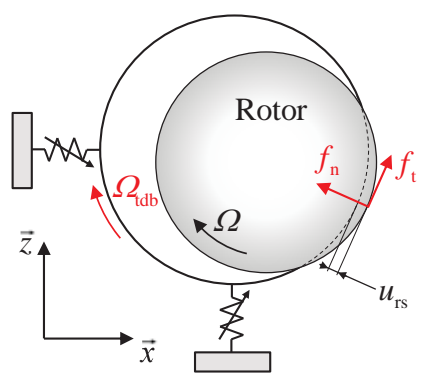

(a) Contact law

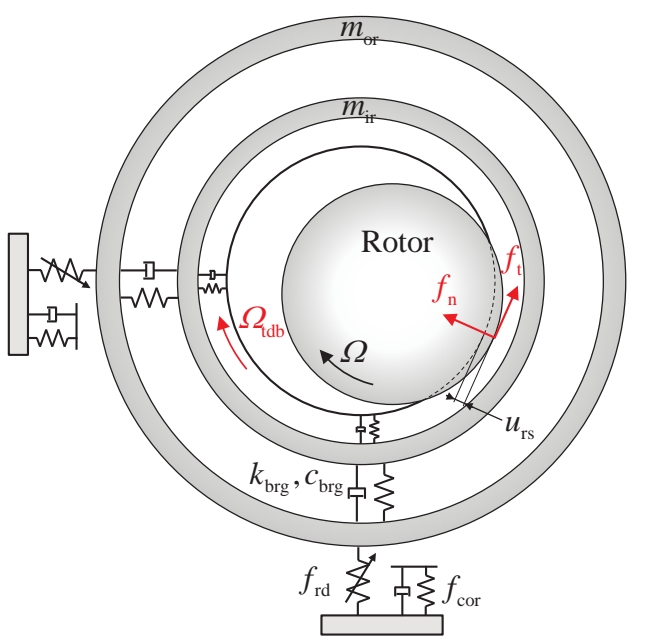

(b) 4-DOF model

Figure 9: TDB models

2. Verifying the previous assumption concerning the identical dynamic behaviour of the ribbon damper subjected either to transient or harmonic loads.

The stator is considered rigid and has no modal contributions. The main differences between these two TDB models lie on whether the TDB lateral dynamics is included. Both models consider vertical and horizontal misalignments, which can influence significantly the rotor dynamic behaviour, as shown in references $[16,17]$. The assumptions of the models are provided in Table 1.

Table 1: TDB models assumptions

\begin{tabular}{lcc}
\hline \hline & Contact law & 4-DOF model \\
Rotor inner race interaction & Rigid & Flexible \\
Ball bearing & Flexible & Flexible \\
Ribbon damper & Flexible & Flexible \\
Housing outer race interaction & Rigid & Flexible \\
Races dynamics & Not considered & Considered \\
\hline \hline
\end{tabular}


Both the models include a similar treatment of the ball bearings dynamic coefficient, especially around zero, and its maximal value is set to 0.2 . The 
ribbon damper, represented by the force $f_{\text {rd }}$, successively includes the previously developed generalized Dahl, see Eq. (1), and the Kelvin-Voigt, see Eq. (4), models. It is possible to analyse the effect of the newly developed dry friction model on the drop dynamics.

\subsection{Contact law model}

The contact law states that the race dynamics are negligible. The ribbon damper comprises the dynamic parameters of the Kelvin-Voigt model in Eq. (4). The related mathematical expression is given by Eq. (12) and a typical forcedeflection loop is plotted in Figure 10; $u_{\mathrm{rs}}$ is the rotor-TDB relative clearance and $u_{\mathrm{rd}}$ is the ribbon crushing capacity.

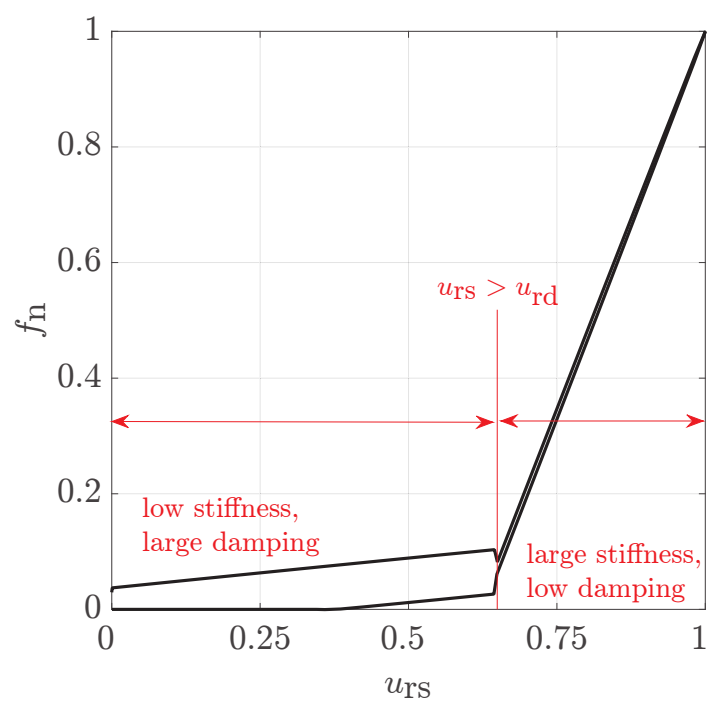

Figure 10: Normalized contact law force-deflection loop

$$
f_{\mathrm{n}}\left(u_{\mathrm{rs}}\right)=\left\{\begin{array}{r}
k_{\mathrm{brg}}\left(u_{\mathrm{rs}}-u_{\mathrm{rd}}\right)+c_{\mathrm{brg}} \dot{u}_{\mathrm{rs}}+k_{\mathrm{eq}} u_{\mathrm{rd}} \quad ; u_{\mathrm{rs}} \geq u_{\mathrm{rd}} \\
k_{\mathrm{eq}} u_{\mathrm{rs}}+c_{\mathrm{eq}} \dot{u}_{\mathrm{rs}} ; u_{\mathrm{rd}}>u_{\mathrm{rs}} \geq 0 \\
0 \quad ; u_{\mathrm{rs}}<0
\end{array}\right.
$$

When the rotor drops, it first contacts the coupled ball bearing ribbon damper system, considered to be in series. The related contact force is composed of the equivalent stiffness $k_{\mathrm{eq}}$ and damping $c_{\mathrm{eq}}$ coefficients. Once the ribbon is fully crushed, meaning that $u_{\mathrm{rs}} \geq u_{\mathrm{rd}}$, the ribbon only has a static contribution and the rotor faces the ball bearing stiffness. This model is characterized 
by high flexibility and large damping when the ribbon is not crushed, followed by high stiffness and low damping as the ribbon bumps collapse, as shown in Figure 10. The tangential force $f_{\mathrm{t}}$ provides the sliding friction force by using the regularized Coulomb model, in Eq. (11), as for the 4-DOF model, and a viscous force, which depends on the rotor tangential speed, counteracting the rotor whirl motions.

Table 2 summarizes features of each TDB models. Two versions of the 4DOF model are used to test the Kelvin-Voigt and the generalized Dahl models.

Table 2: Tested TDB models

\begin{tabular}{c|c|c|c|}
\hline \multirow{2}{*}{ TDB model } & Contact law & \multicolumn{2}{|c|}{ 4-DOF } \\
\cline { 2 - 4 } & Model \#1 & Model $\# 2$ & Model \#3 \\
\hline \hline $\begin{array}{c}\text { Rotor inner } \\
\text { race } \\
\text { interaction }\end{array}$ & Rigid & Hunt and Crossley $f_{\mathrm{n}}$ in Eq. (10) \\
\hline $\begin{array}{c}\text { Ball bearing } \\
\text { Ribbon } \\
\text { damper }\end{array}$ & \multicolumn{2}{|c|}{ Dynamic parameters $k_{\text {brg }}, c_{\text {brg }}$} \\
\hline $\begin{array}{c}\text { Housing } \\
\text { outer race } \\
\text { interaction }\end{array}$ & Rigid & Goneralized \\
\hline \hline
\end{tabular}

\section{Industrial scale test rig}

To validate the TDB models, rotor drop tests were performed with the industrial scale test rig, shown in Figure 11(a), equipped with a 5-axis AMB system.

The test platform is modular and can be used with different rotor configurations. The heteropolar AMBs are powered in differential driving mode with a 6 


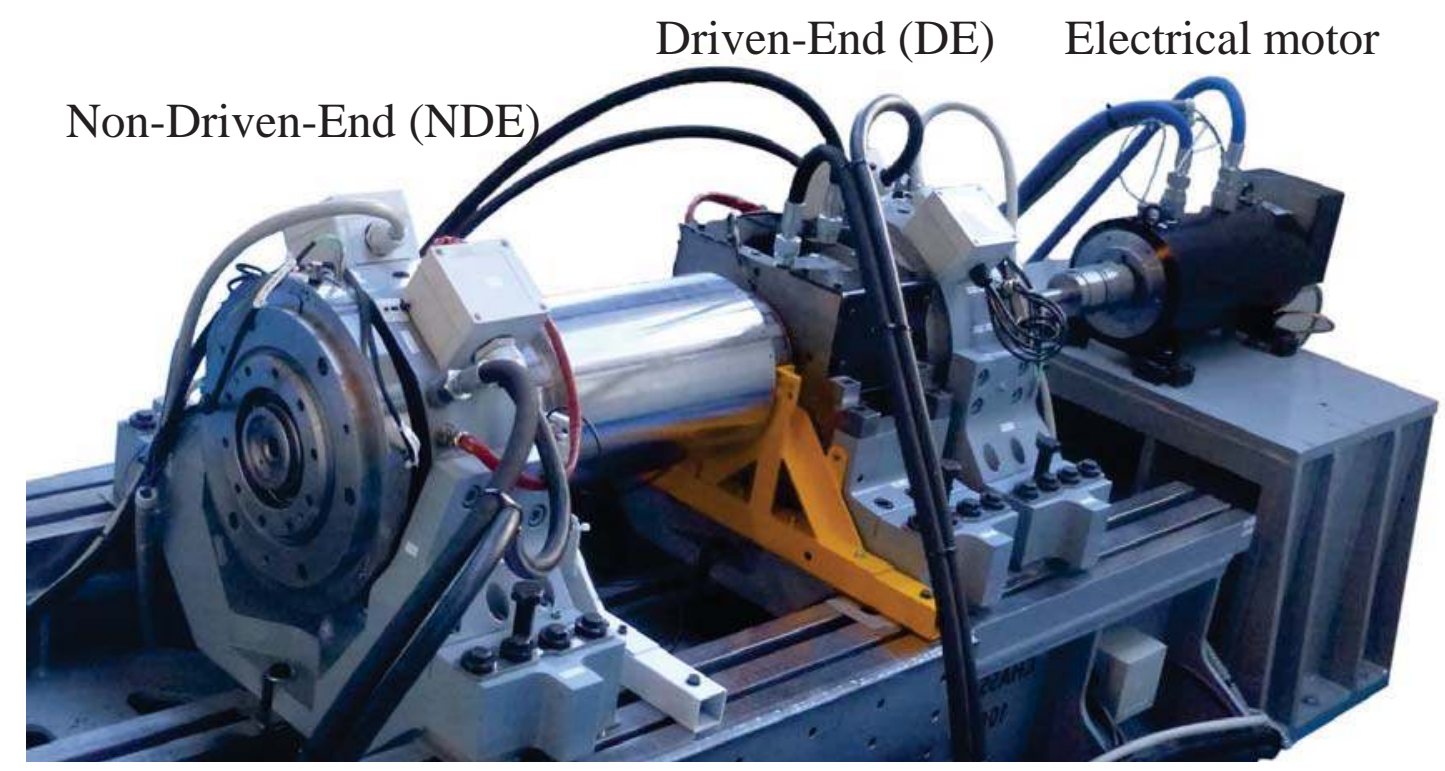

(a) Photo of the industrial test bench

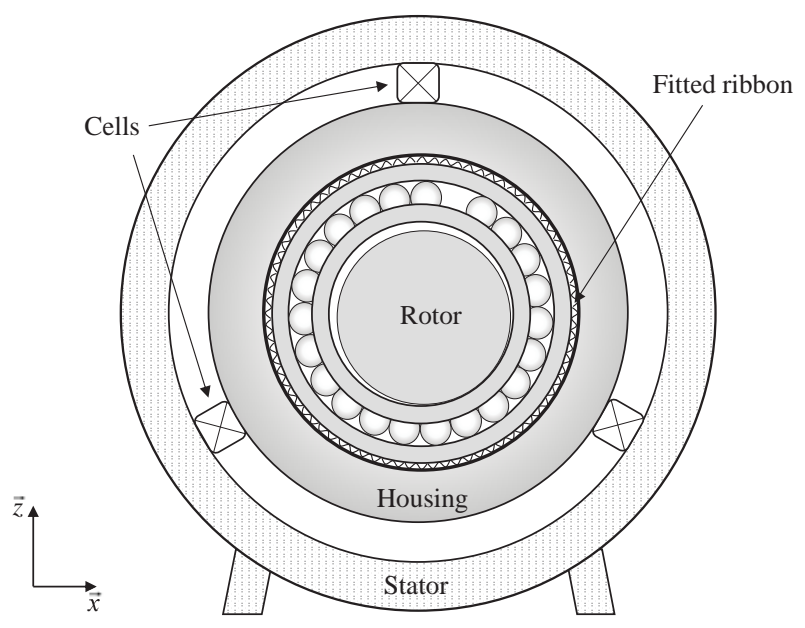

(b) Scheme of the load cells locations

Figure 11: Industrial test bench and assembly

A bias current. Forced air cooling is used to dissipate bearing losses mainly due to windage. The rotor has a $200 \mathrm{~kg}$ mass and a $0.97 \mathrm{~kg} . \mathrm{m}^{2}$ rotational inertia. It was designed to have its first flexible mode above $25000 \mathrm{rpm}$. The 1150 $\mathrm{mm}$ long rotor is driven by an electrical motor through a flexible coupling, and the driven-end (DE) and non-driven-end (NDE) actuators span is $787 \mathrm{~mm}$. The rotor is $230 \mathrm{~mm}$ in diameter at the mid-span section. Inductive sensors installed next to the AMB's measured the rotor DE and NDE displacements. The test 
bench TDBs are the one used in the calculation of the load-deflection relationship in Subsection 3.1. Their equivalent rotational inertias are $2.2 \times 10^{-3} \mathrm{~kg} . \mathrm{m}^{2}$. TDBs are monitored with triaxial accelerometers and three pre-loaded force cells located between the stator and housing (120 apart), as shown in Figure 11(b). In this configuration, the load cells measure only radial forces and the drops loads are entirely transmitted to the stator through these load cells. Measurements of the TDB rotational speed were not available. The sampling frequency is $20 \mathrm{kHz}$ which is sufficient to analyse nonlinear dynamics phenomena.

The rotor is modelled with 41 Timoshenko beam elements for a total mesh of 168 DOF for the lateral analysis, see Figure 12.

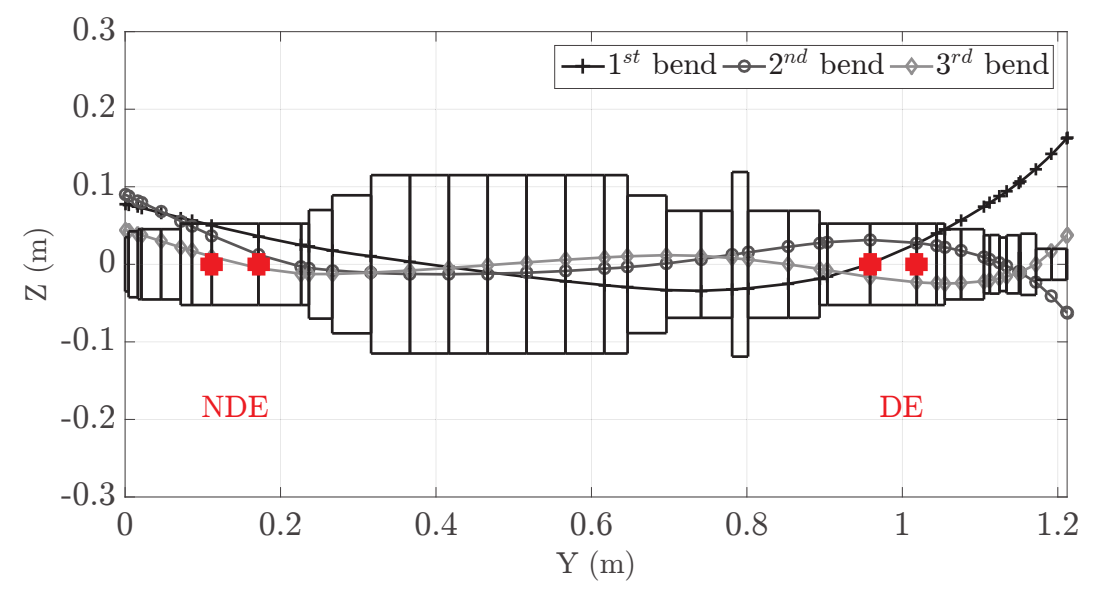

Figure 12: Industrial test bench shaft FE model and the first three FE in-plane mode shapes

The equations of motion have the following form:

$$
\mathbf{M} \ddot{\boldsymbol{\delta}}+(\Omega \mathbf{G}+\mathbf{C}) \dot{\boldsymbol{\delta}}+\left(\dot{\Omega} \mathbf{K}_{\mathrm{G}}+\mathbf{K}\right) \boldsymbol{\delta}=\mathbf{F}_{\mathrm{mu}}+\mathbf{F}_{\mathrm{g}}+\mathbf{F}_{\mathrm{amb}}+\mathbf{F}_{\mathrm{c}}
$$

with $\mathbf{M}, \mathbf{K}, \mathbf{G}$ and $\mathbf{C}$ the mass, the shaft stiffness, the gyroscopic and the damping matrices, respectively. The nodal displacement vector is $\boldsymbol{\delta}$. The rotor is decelerated by the TDB friction forces; the transient effects associated with the variable speed of rotation are considered through the matrix $\mathbf{K}_{\mathrm{G}}$, see Lalanne and Ferraris [49]. The mass unbalance force vector $\mathbf{F}_{\mathrm{mu}}$ takes into account the normal and tangential forces associated with constant and variable rotational speeds, respectively. The effect of gravity is also considered in the 
force vector $\mathbf{F}_{\mathrm{g}}$. The magnetic and the TDBs contact force vectors are $\mathbf{F}_{\mathrm{amb}}$ and $\mathbf{F}_{\mathrm{c}}$, respectively. No control loop is activated; the AMB stiffness and damping parameters are provided by the controller transfer function for a given shaft rotational speed.

A pseudo-modal method is used to reduce the model size. Only the first 12 modes are kept since simulations carried out with higher number of modes have shown that their contributions were negligible on the rotor transient response. The first three bending modes are plotted in Figure 12. Using the modal method facilitates the introduction of the modal ratio taken as $\alpha_{\psi}=0.005$ for all the modes included. The flexible coupling stiffness and damping are neglected and only the portion attached to the rotor is modelled as an added mass and inertia at the DE side.

\section{Rotor drop dynamics investigations}

Experimental results from rotor drop tests without rotation and at 6500 rpm were obtained to validate the TDB model. In the test without rotation, the rotor is only subjected to gravity (no unbalance or gyroscopic forces) and this allows to benchmark the model against maximal vertical rebound heights and drop loads in order to select the best TDB model. The test at $6500 \mathrm{rpm}$ provides the time required for the TDB to reach full speed, which is used to validate the selected model.

Numerical simulations over a $1 \mathrm{~s}$ time interval are performed by using the $5^{\text {th }}$ order Runge-Kutta explicit scheme with a $5 \mu$ s time step for nonlinear analysis. At $0.2 \mathrm{~s}$, AMBs restoring forces are set to zero. Rotor displacements and TDB loads results are normalized respectively according to the rotor-TDB clearance and to the maximal load observed during the ribbon experimental characterization, see Figure 5. Models \#1, \#2 and \#3 are implemented in the simulation successively. 


\subsection{TDB model selection - drop at rest}

Table 2, are compared with the test in Figures 13, 14 and 15, respectively. In particular, the rotor displacements/orbits and contact forces along the z-axis at both NDE and DE positions are presented.

Regarding the contact law model, prediction of vertical displacements and orbital motions correlate well with experimental datas, especially at the DE side, see Figure 13. At the NDE side, the predicted journal rebound and penetration depth are higher than experimental results. The predicted DE side loads are close in amplitude to experimental results, but not in duration while at the NDE side, loads are partially well captured up to $0.017 \mathrm{~s}$.

The 4-DOF model using the Kelvin-Voigt law, see Figure 14, and the contact law, see Figure 13, show similar results; the rotor-TDB-housing interaction yields high contact stiffness, much greater than the ribbon outer race interaction.

The results predicted with the generalized Dahl model are plotted in Figure 15. For both NDE and DE sides, the predicted rebounds are flattened; this is due to the high level of damping brought by the dry friction generated in the ribbon damper model. The final static positions of the rotor at the bottom of its TDBs are not identical. The loads are better predicted than those coming from the Kelvin-Voigt model even if stick-slip transitions are much more visible than in experiments: the two slopes are clearly visible at the DE side, see Figure $15(\mathrm{~d})$.

The previously developed generalized Dahl model, benchmarked to harmonic tests performed on the ribbon damper, provides mixed results in terms of rotor drop dynamics; it generates too much damping and drop rebounds are flattened. This is attributed to the fact that the dynamic behaviour of the ribbon is probably different when subject to shocks instead of harmonic excitations. Shocks could more easily unstick the ribbon bumps leading to a decrease of the slipping threshold $\mu F_{\mathrm{N}}$, in Eq. (3), and to a reduction of the damping in the system drop. This hypothesis is sustained by the fact that slipping threshold is 


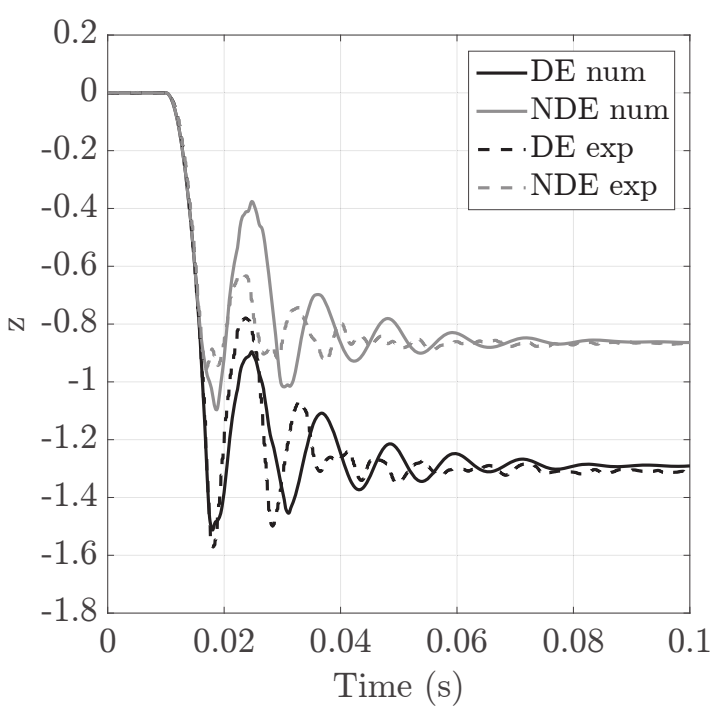

(a) Vertical drop

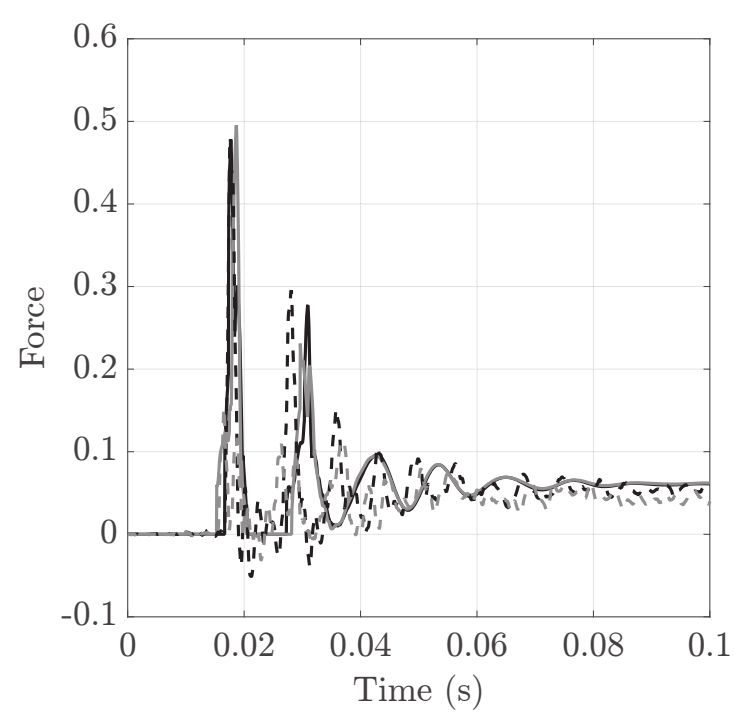

(c) Drop loads

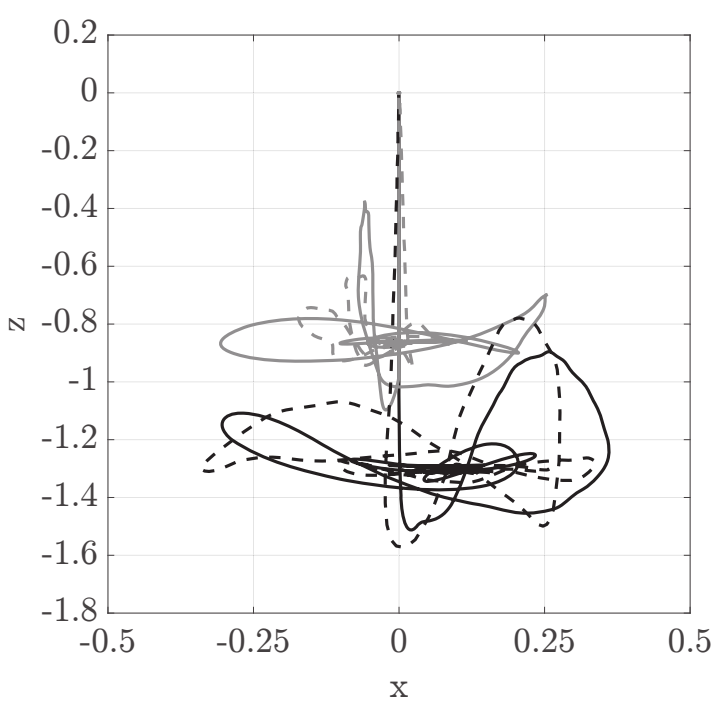

(b) Orbits

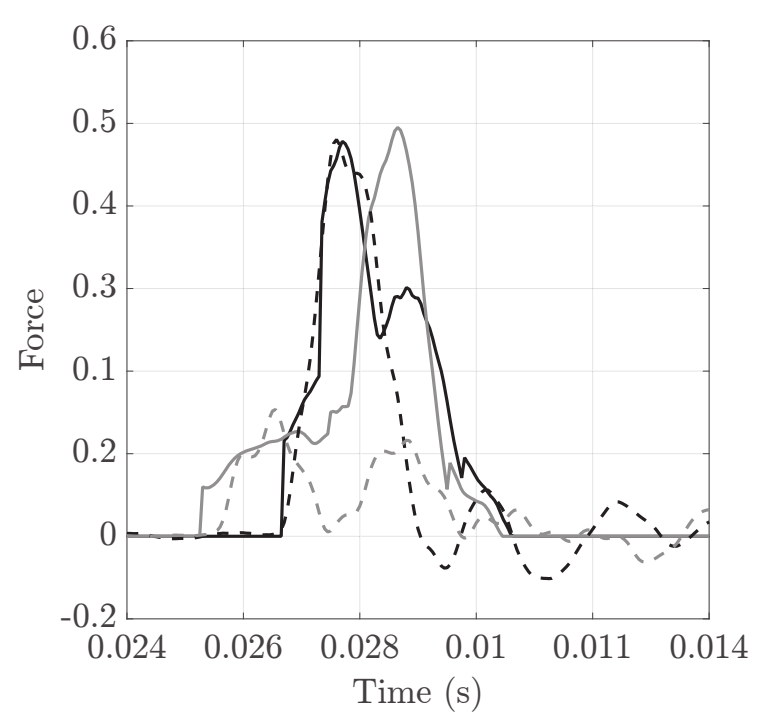

(d) Drop loads zoom

Figure 13: Model \#1, see Table 2 - Normalized predicted (solid lines) vs measured (dotted lines) results, drop at $0 \mathrm{rpm}$

significantly smaller on the DE side where the rotor drops from a position 50 $\%$ higher than in the NDE side. The generalized Dahl model could be certainly improved by an adaptive model where the parameters would be dependent on the impact velocity. As the slipping threshold seems to be completely reduced, viscous damping instead of dry friction is able to describe the transient drop events.

In order to improve the numerical simulation, the slipping threshold $\mu F_{\mathrm{N}}$ of 


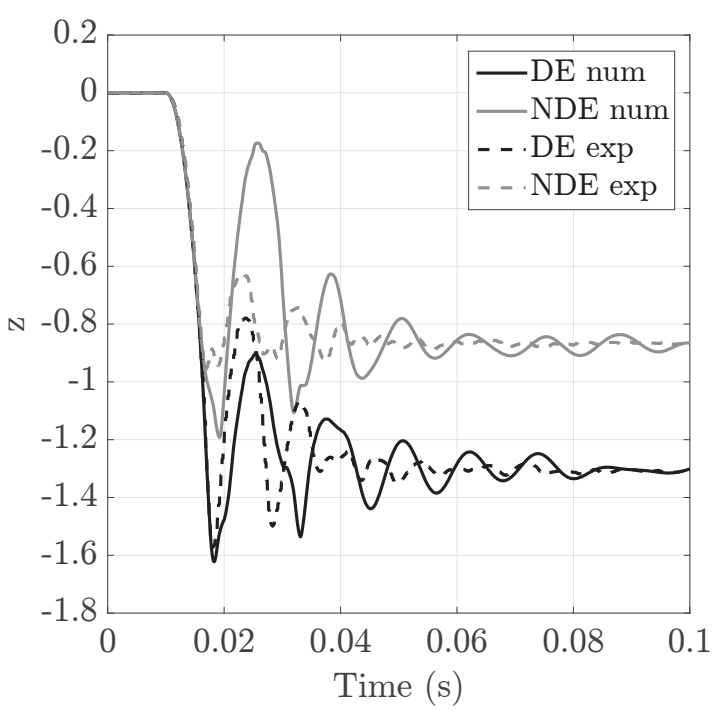

(a) Vertical drop

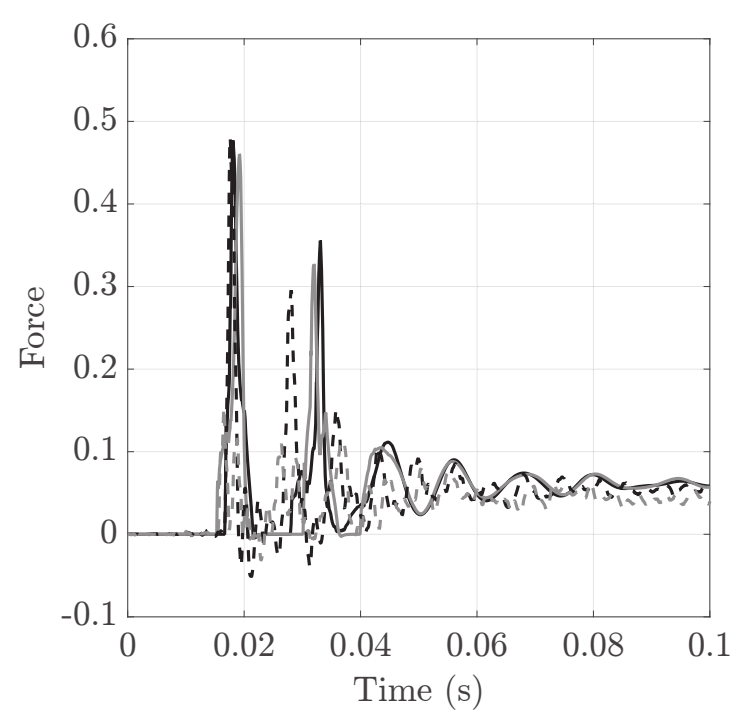

(c) Drop loads

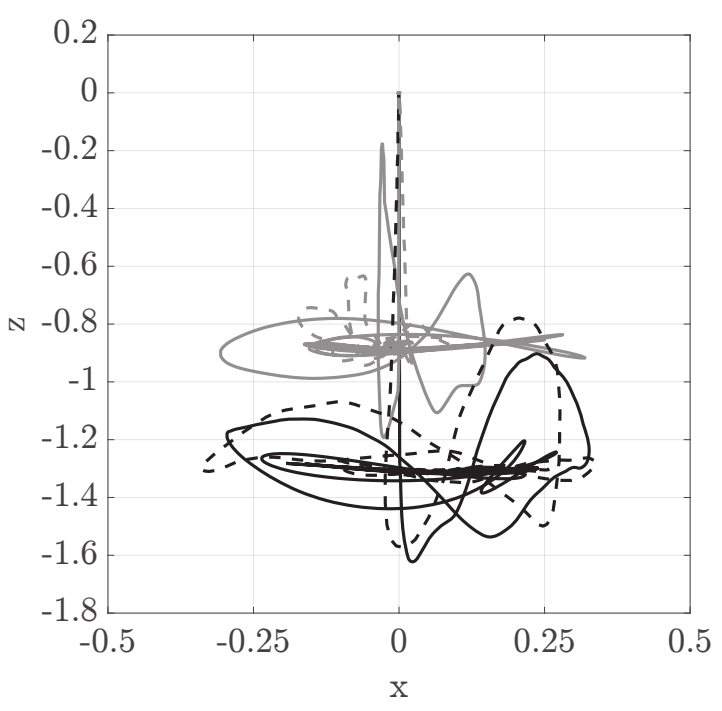

(b) Orbits

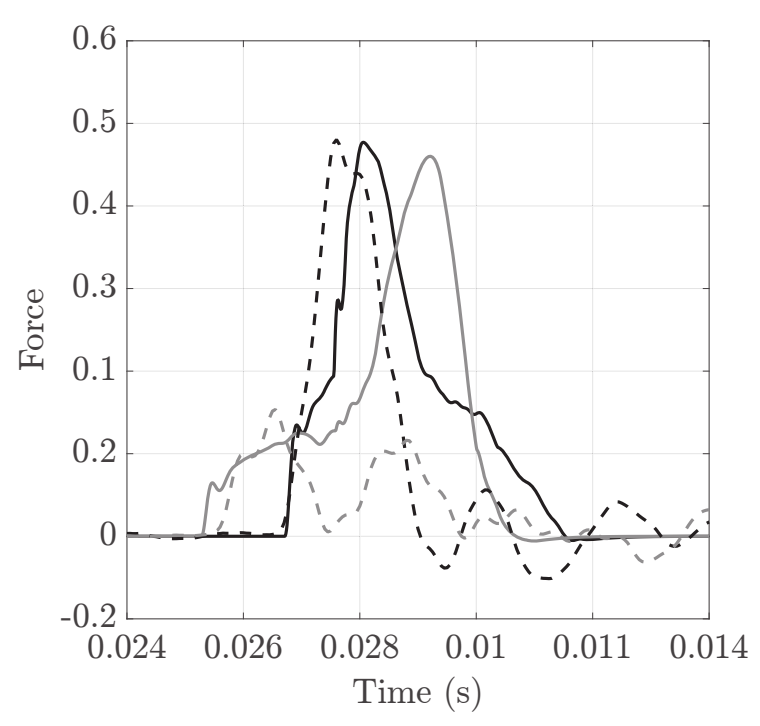

(d) Drop loads zoom

Figure 14: Model \#2, see Table 2 - Normalized predicted (solid lines) vs measured (dotted lines) results, drop at $0 \mathrm{rpm}$

the generalized Dahl model related to the upper and lower envelops is decreased at both DE and NDE sides.

Figure 16 shows the effect of decreasing the slipping threshold on the rotor drop dynamics in terms of orbits and hysteresis loops. Predicted rotor rebound amplitudes are closer to experimental results, especially at the DE side. The parameter $\mu F_{\mathrm{N}}$ was reduced by a factor of 30 and 4 at the DE and NDE sides, respectively. The ribbon hysteresis loop surfaces are then reduced implying 


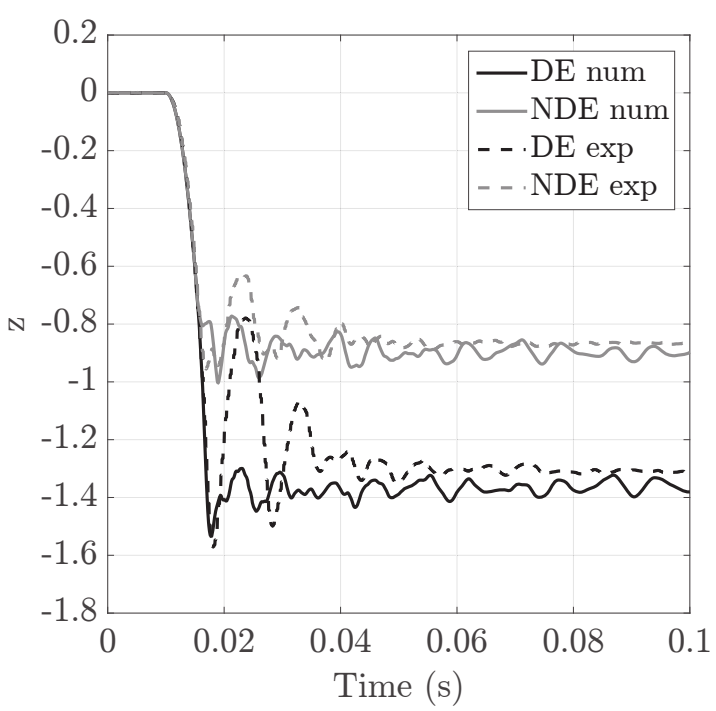

(a) Vertical drop

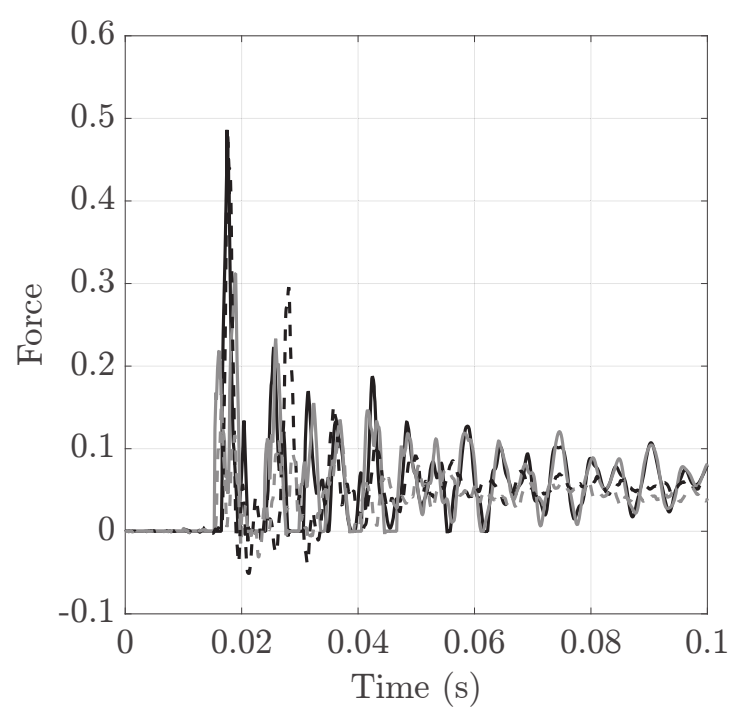

(c) Drop loads

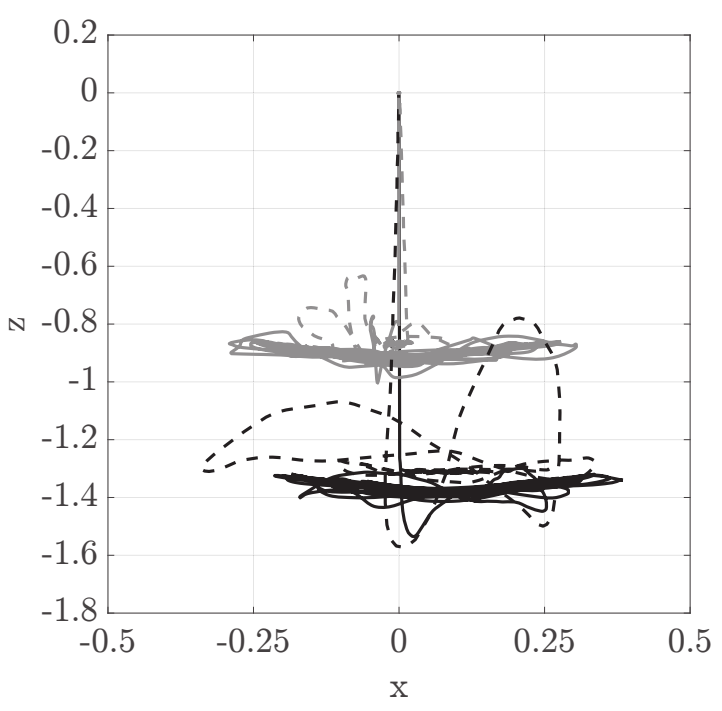

(b) Orbits

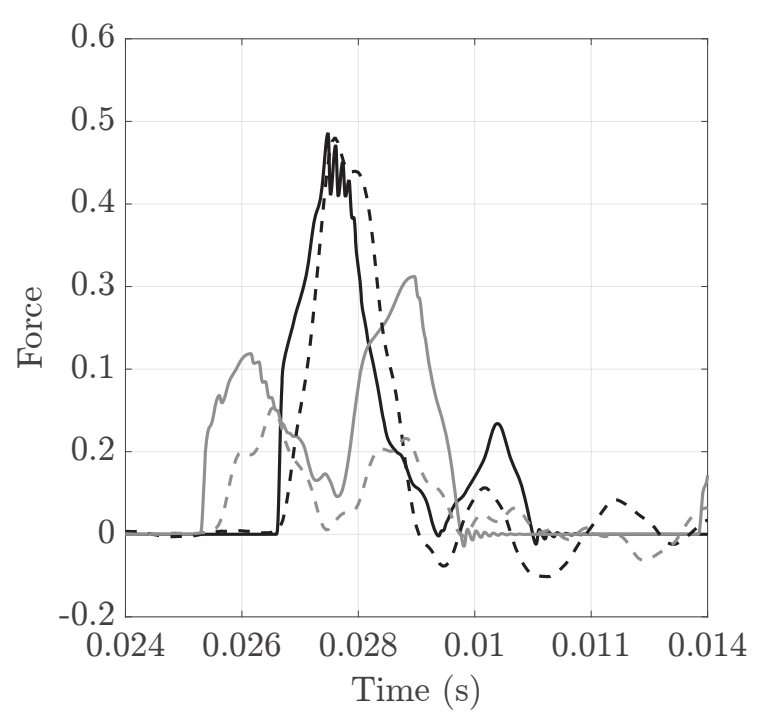

(d) Drop loads zoom

Figure 15: Model \#3, see Table 2 - Normalized predicted (solid lines) vs measured (dotted lines) results, drop at $0 \mathrm{rpm}$

a global reduction of the dissipated energy and corresponding damping. The modified ribbon parameters significantly improved the correlation between predictions and experimental results.

From Figures 13 to 16, it seems reasonable to conclude that the simple contact law is a plausible approach considering the requirements of this research project. The predicted orbits comparisons between the contact law and the 4-DOF model by using the Kelvin-Voigt model have shown that the contribu- 


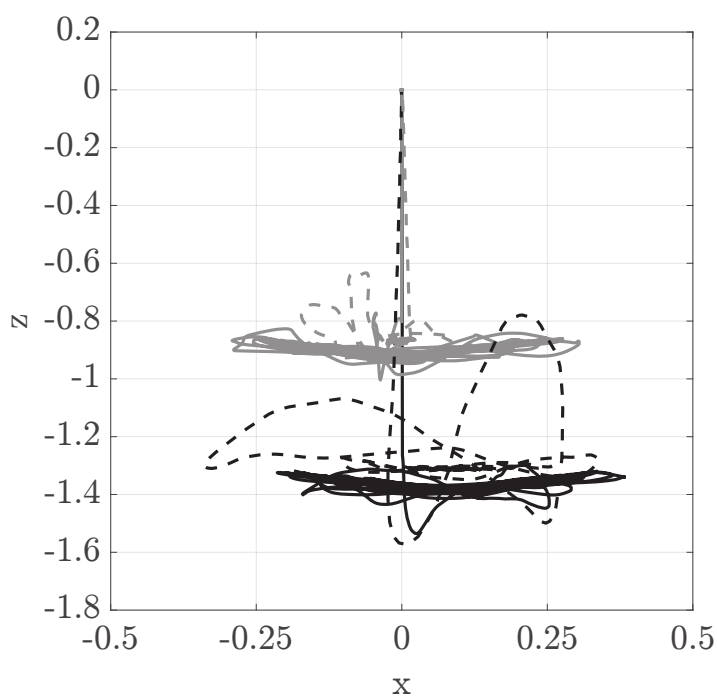

(a) Orbit with initial threshold

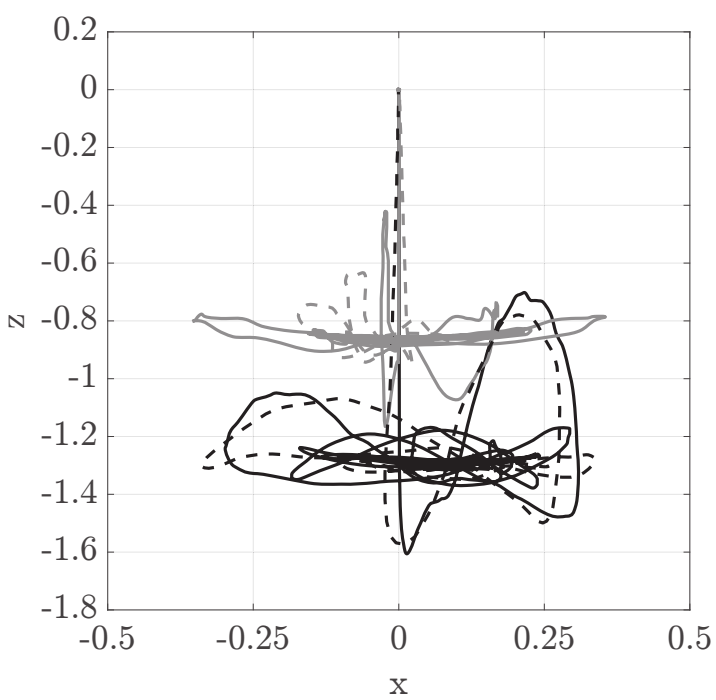

(c) Orbit with modified threshold

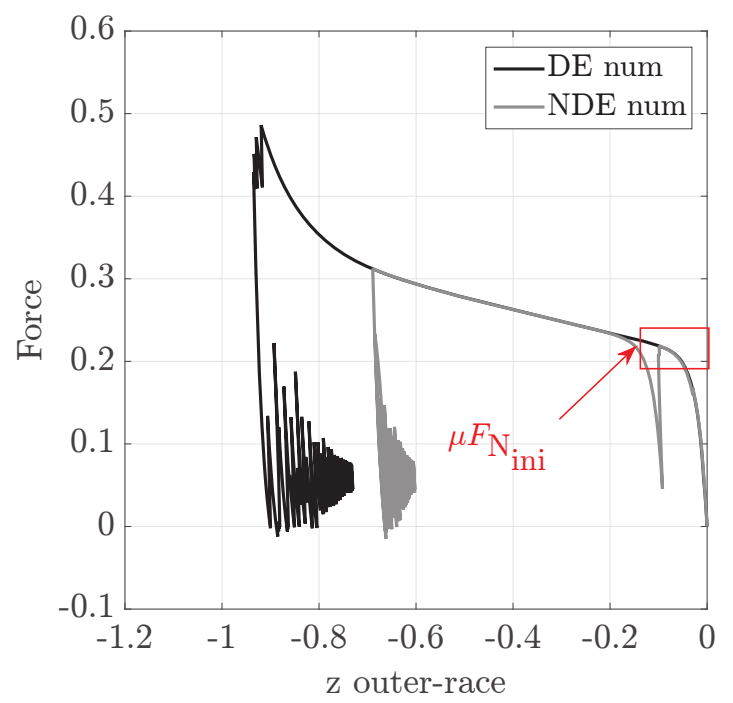

(b) Force-deflection loop with initial threshold

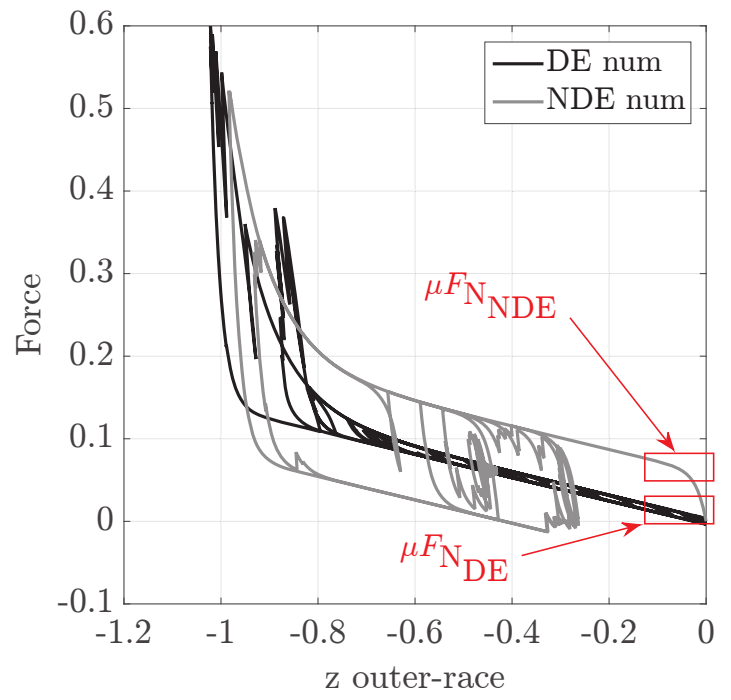

(d) Force-deflection with modified threshold

Figure 16: Model \#3, see Table 2, with initial ( $\mathrm{a}, \mathrm{b}$ ) and reduced (c, d) slipping threshold Normalized predicted (solid lines) vs measured (dotted lines) results, drop at $0 \mathrm{rpm}$

tion of rotor inner race and outer race housing interactions can be considered negligible in this case. This is especially true for the industrial rotating machinery where the rotor is heavy compared to TDBs. Finally, the behaviour of the ribbon damper showed different characteristics when subjected to harmonic or transient excitations. The drop of the rotor at rest permits selecting and validating the TDB model in lateral direction. To validate the rotational 
modelling, predictions and measures of the lateral dynamics of a spinning rotor during drop are compared.

\subsection{Rotational validation - drop at 6500 rpm} s of the sampled data and the friction forces drive the TDBs until reaching the rotor speed.

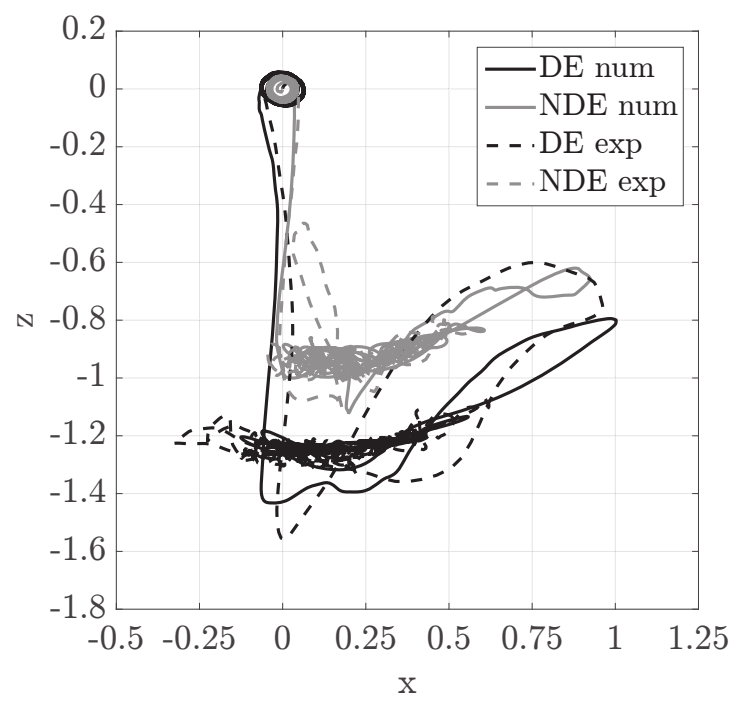

Figure 17: Model \#1, see Table 2 - Normalized predicted (solid lines) vs measured (dotted lines) orbits, drop at $6500 \mathrm{rpm}$

Figure 17 shows the normalized measured and predicted orbits from the contact law TDB model. The transient drop dynamics, characterized by multiple rebounds, quickly stabilizes and the rotor reaches its equilibrium position at the bottom of the TDBs. Qualitatively, predicted and experimental results correlate well.

Horizontal displacements are presented in Figure 18 showing that the global dynamic behaviour from experiments is well reproduced by predictions. It is worth mentioning that the first horizontal motion of the rotor just after the drop is described well at the DE side. The most important information from the tests lies in the change of dynamics, occurring close to $0.3 \mathrm{~s}$ and visible in both the predictions and experiments. The rotor is recentred at the bottom of its TDBs; this corresponds to the moment where the TDBs reach the rotor speed, as shown 


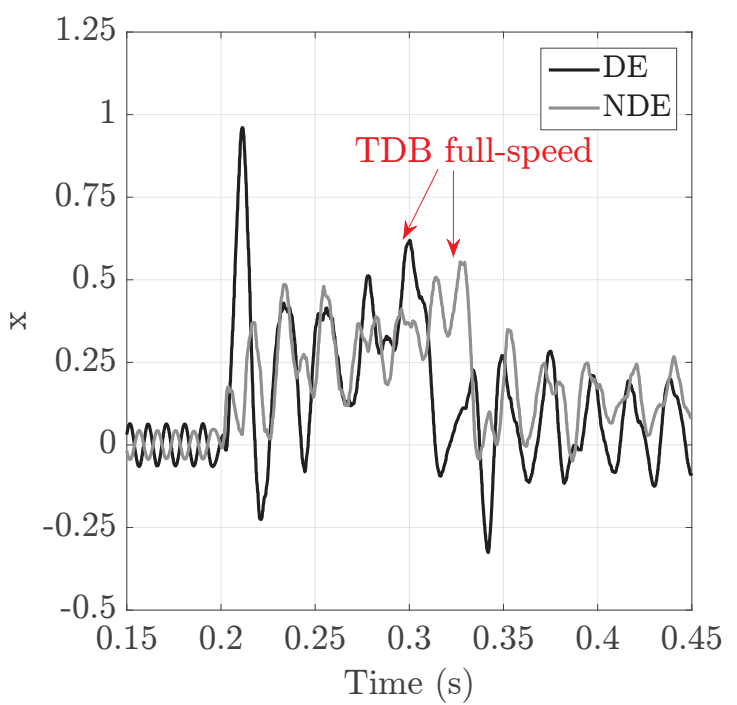

(a) Experimental results

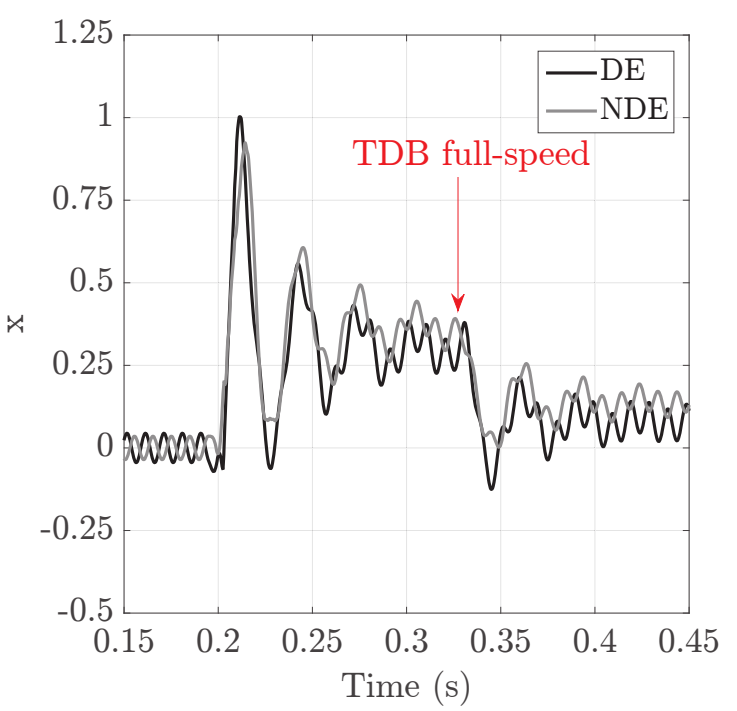

(b) Numerical results

Figure 18: Model \#1, see Table 2 - Normalized measured (a) and predicted (b) horizontal rotor displacements, drop at $6500 \mathrm{rpm}$

in Figure 19(a). At this moment, the tangential friction forces become close to zero since the relative velocity is nil. The DE touchdown bearing seems to reach full speed earlier.

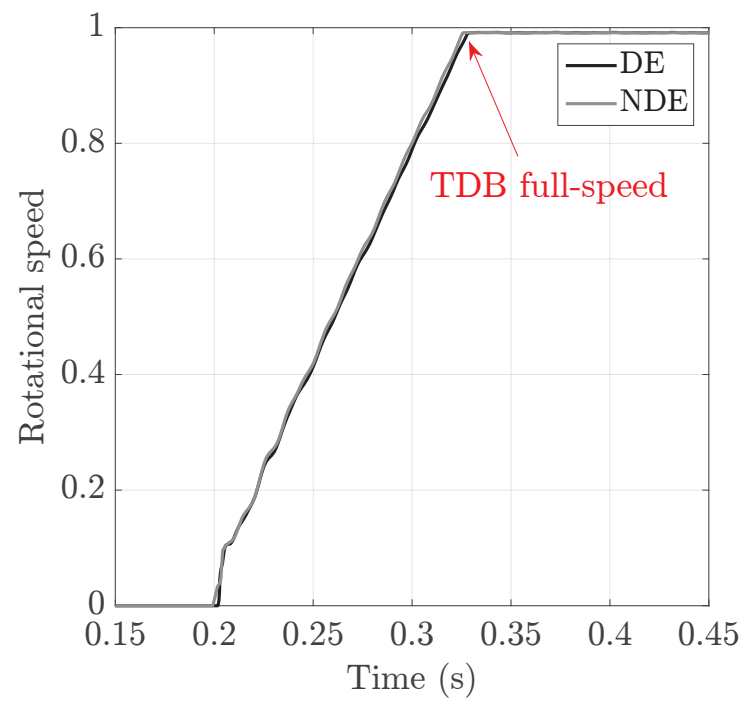

(a) TDB rotational speed

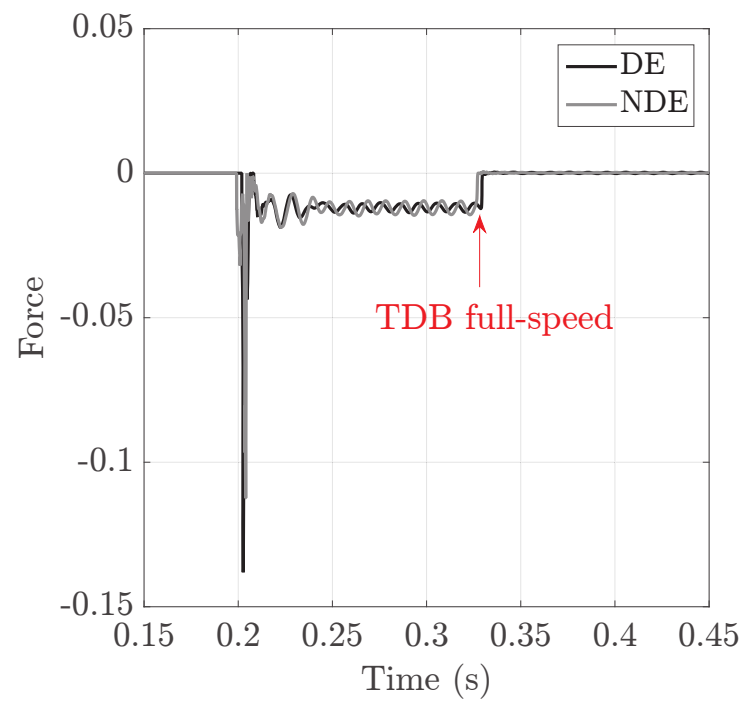

(b) Tangential contact loads

Figure 19: Model \#1, see Table 2 - Normalized predicted TDB rotational speed (a) and predicted tangential contact loads (b), drop at $6500 \mathrm{rpm}$ 
Table 3 provides the measured vs predicted times at which the TDBs reaches the rotor speed. These results correlate well and show the ability of the rotational modelling to describe correctly the spin-up of TDBs. The observed phenomenon echoes the results from Kärkkäinen et al. [20] and Helfert et al. [30], thus the assumptions concerning rolling-without-slipping kinematic conditions seems to be valid.

Table 3: Predicted vs measured TDB times to reach full-speed and the relative deviations

\begin{tabular}{ccc}
\hline \hline & Experiments & Model \\
\hline $\mathrm{DE}$ & $0.11 \mathrm{~s}$ & $0.125 \mathrm{~s} /+14 \%$ \\
$\mathrm{NDE}$ & $0.129 \mathrm{~s}$ & $0.126 \mathrm{~s} /-3 \%$ \\
\hline \hline
\end{tabular}

The deviations between experimental and predicted orbits, plotted in Figure 17, may be attributable to rotation effects since rotor drop predictions at rest provided relatively good results. Since the rotor has no large discs, gyroscopic effect is weak and cannot explained the deviation. The sliding friction is a crucial parameter of drop dynamics. However, the value of the friction coefficient was set to 0.2 which is the order of magnitude. In Figure 17, the first rebound in the $\mathrm{x}$-direction is driven mostly by friction effects. At the DE side, the latter reaches almost the normalized value of one for both the predictions and the measurements; the friction coefficient may not be the main cause of deviations here.

It is well-known that the mass unbalance (amplitude, phase and distribution) can lead to completely different rotor transient behaviours during drops. A numerical assessment is carried out to analyse the effect of the phase angle on the transient nonlinear drop dynamics. For an identical mass unbalance located at the coupling, the associated phase angle at the moment of drop is modified from $0^{\circ}$ to $270^{\circ}$. The influence in terms of rotor orbit is plotted in Figure 20 . It is shown that depending on the phase angle, the rebound paths are different.

It is then reasonable to assume that discrepancy between predictions and experiments arises from uncertainty of the unbalance distribution. 


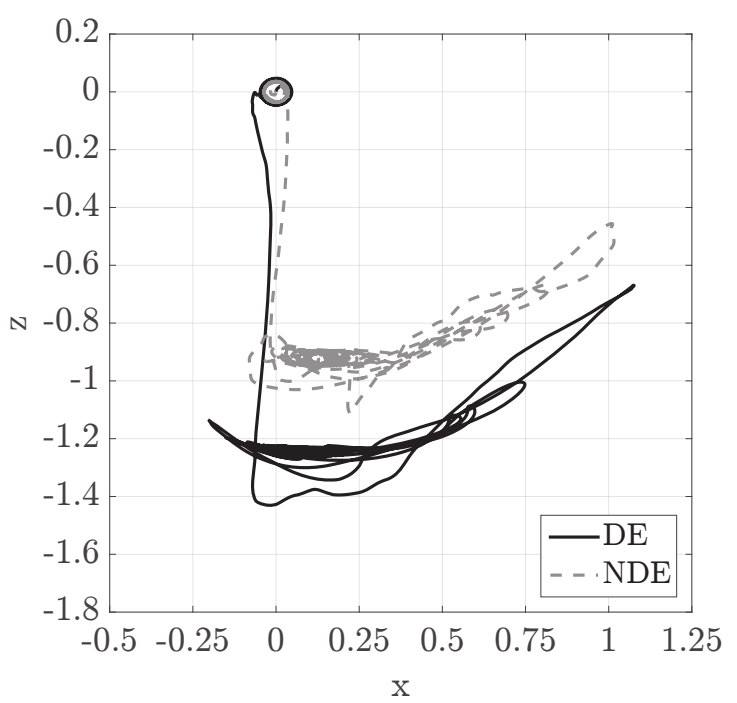

(a) Unbalance phase angle: $0^{\circ}$

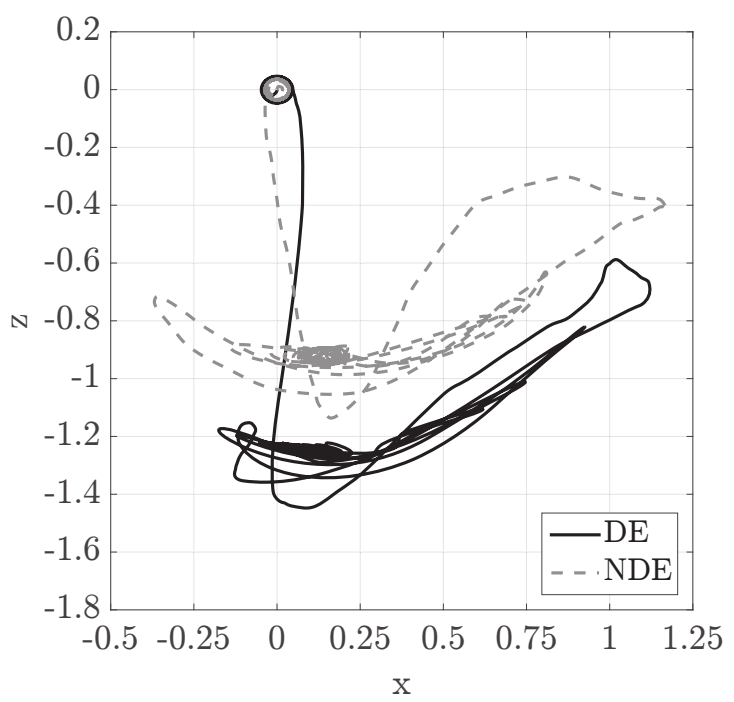

(c) Unbalance phase angle: $180^{\circ}$

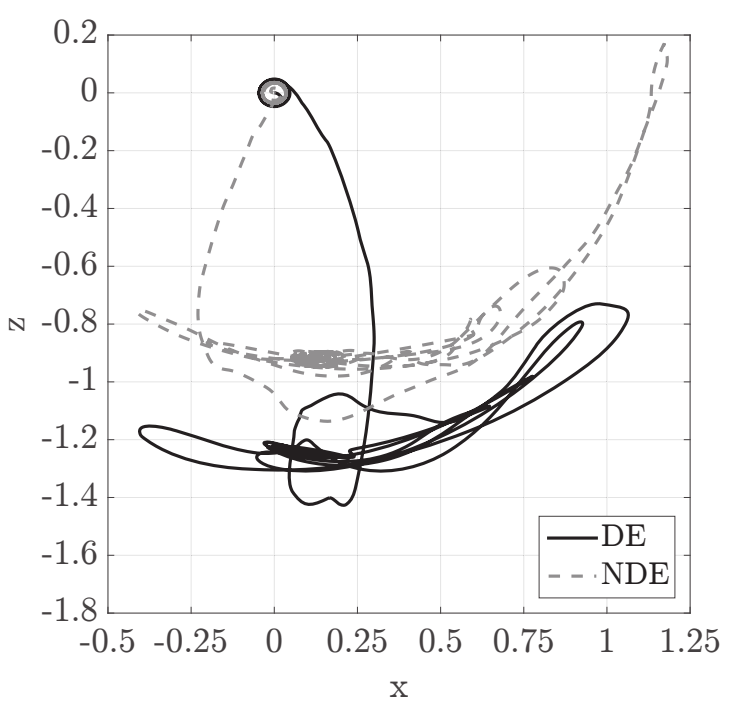

(b) Unbalance phase angle: $90^{\circ}$

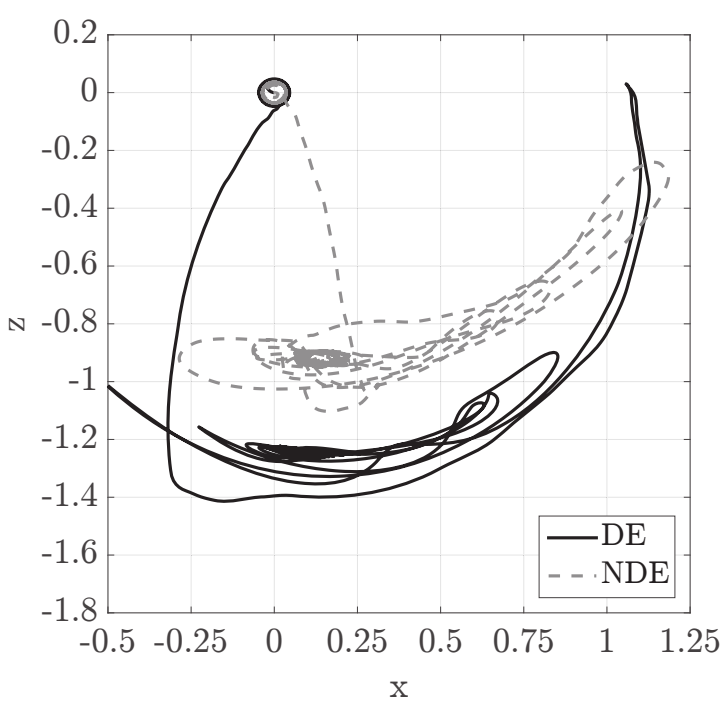

(d) Unbalance phase angle: $270^{\circ}$

Figure 20: Model \#1, see Table 2 - Normalized predicted orbits for different unbalance phase angle, drop at $6500 \mathrm{rpm}$

\section{Conclusions}

The rotor drop response was investigated theoretically and experimentally in order to provide a model as accurate as possible. A particular effort was done concerning the degree of detail required for the TDB model to represent with sufficient accuracy the measured rotor displacements. For the need of this study, a sufficiently representative model was required. Three TDB models were 
tested. The experimental validation was performed on an industrial scale test

\section{References}

[1] G. Schweitzer, E. H. Maslen, Magnetic Bearings, Theory, Design, and Application to Rotating Machinery, Springer-Verlag, 2009.

[2] A. R. Bartha, Dry friction backward whirl of rotors, Phd thesis, ETH Zürich, 2000. 
[11] Y. S. Choi, Investigation on the whirling motion of full annular rotor rub, Journal of Sound and Vibration 258 (2002) 191-198.

[4] G. Sun, A. B. Palazzolo, A. Provenza, G. Montague, Detailed ball bearing model for magnetic suspension auxiliary service, Journal of Sound and Vibration 269 (2004) 933-963.

[5] G. Sun, Rotor drop and following thermal growth simulations using detailed auxiliary bearing and damper models, Journal of Sound and Vibration 289 (2006) 334-359.

[6] L. Hawkins, P. McNullen, V. Vuong, Development and testing of the backup bearing system for an amb energy storage flywheel, in: Proceedings of the ASME Turbo Expo 2007: Power for Land, Sea and Air, Montreal, Canada, 2007.

[7] D. Ransom, A. Masala, J. Moore, G. Vannini, M. Camatti, Numerical and experimental simulation of a vertical high speed motorcompressor rotor drop onto catcher bearings, Journal of System Design and Dynamics 3 (2009) 596-606.

[8] J. Wilkes, J. Moore, D. Ransom, G. Vannini, An improved catcher bearing model and an explanation of the forward whirl / whip phenomenon observed in amb transient drop experiments, Journal of Engineering for Gas Turbines and Power 136 (2014) 504-515.

[9] H. F. Black, Interaction of a whirling rotor with a vibrating stator across a clearance annulus, Journal of Mechanical Engineering Science 10 (1968).

[10] A. Lingener, Investigation of reverse whirl of flexible rotor, Rakenteiden Mekaniikka 24 (1991) 3-21. 
[12] D. W. Childs, A. Bhattacharya, Prediction of dry-friction whirl and whip between a rotor and a stator, Journal of Vibration and Acoustics 129 (2007) $355-362$.

[13] L. Xie, S. Baguet, B. Prabel, R. Dufour, Numerical tracking of limit points for direct parametric analysis in nonlinear rotordynamics, Journal of Vibration and Acoustics 138 (2016) 021007.

[14] A. Gelin, J. M. Pugnet, J. Der Hagopian, Dynamic behavior of flexible rotors with active magnetic bearings on safety auxiliary bearings, in: Proceedings of the $3^{\text {rd }}$ IFToMM International Conference on Rotordynamics, Lyon, France, 1990.

[15] L. A. Hawkins, A. Filatov, S. Imani, D. Prosser, Test results and analytical predictions for rotor drop testing of an active magnetic bearing expander/generator, Journal of Engineering for Gas Turbines and Power 129 (2006) 522-529.

[16] P. S. Keogh, M. O. Cole, Contact dynamic response with misalignment in a flexible rotor/magnetic bearing system, Journal of Engineering for Gas Turbines and Power 128 (2006) 362-369.

[17] O. Halminen, A. Kärkkäinen, J. Sopanen, A. Mikkola, Active magnetic bearing-supported rotor with misaligned cageless backup bearings: A dropdown event simulation model, Mechanical Systems and Signal Processing 50-51 (2015) 692-705.

[18] E. H. Maslen, L. E. Barrett, Rotor whirl in compliant auxiliary bearings, Journal of Vibration and Control 2 (1996) 145-159.

[19] R. G. Kirk, E. J. Gunter, W. J. Chen, Rotor drop transient analysis of amb machinery, in: Proceedings of the ASME IDETC/CIE 2005, New Orleans, USA, 2005. 
[20] A. Kärkkäinen, J. Sopanen, A. Mikkola, Dynamic simulation of a flexible rotor during drop on retainer bearings, Journal of Sound and Vibration 306 (2007) 601-617.

[21] G. Siegl, T. Tzianetopoulou, J. Denk, Simulation and experimental validation of a 9 ton amb rotor landing in rolling element back-up bearings, Mechanical Engineering Journal 3 (2016) 15-00136-15-00136.

[22] H. Xie, G. T. Flowers, L. Feng, C. Lawrence, Steady-state dynamic behavior of a flexible rotor with auxiliary support from a clearance bearing, Journal of Vibration and Acoustics 121 (1999) 78-83.

[23] Y. Ishida, T. Inoue, Vibration characteristics of a rotor system in contact with a backup bearing: Cases with various failure patterns of the active magnetic bearing, Journal of Vibration and Control 14 (2008) 571-589.

[24] T. Ishii, R. G. Kirk, Transient response technique applied to active magnetic bearing machinery during rotor drop, Journal of Vibration and Acoustics 118 (1996) 154-163.

[25] R. G. Kirk, Evaluation of amb turbomachinery auxiliary bearings, Journal of Vibration and Acoustics 121 (1999) 156-161.

[26] S. Zeng, Modelling and experimental study of the transient response of an active magnetic bearing rotor during rotor drop on back-up bearings, Proceedings of the Institution of Mechanical Engineers, Part I: Journal of Systems and Control Engineering 217 (2003) 505-517.

[27] P. Siebkea, H. Golbachb, A novel rolling element back-up bearing for a $9 \mathrm{t}$ rotor application, in: Proceedings of the $14^{\text {th }}$ International Symposium on Magnetic Bearings, Linz, Austria, 2014.

[28] M. O. T. Cole, P. S. Keogh, C. R. Burrows, The dynamic behavior of a rolling element auxiliary bearing following rotor impact, Journal of Tribology 124 (2001) 406-413. 
[29] J. G. Lee, A. Palazzolo, Catcher bearing life prediction using a rainflow counting approach, Journal of Tribology 134 (2012) 031101-031101.

[30] M. Helfert, M. Ernst, R. Nordmann, B. Aeschlimann, High-speed video analysis of rotor-retainer-bearing-contacts due to failure of active magnetic bearings, in: Proceedings of the $10^{\text {th }}$ International Symposium on Magnetic Bearing, Martigny, Switzerland, 2006.

[31] C. Jarroux, R. Dufour, J. Mahfoud, B. Defoy, T. Alban, A. Delgado, On the drop of a rotor-amb system onto touch-down bearing, in: Proceedings of the $11^{\text {th }}$ IMechE International Conference on Vibrations in Rotating Machinery, Manchester, United Kingdom, 2016.

[32] E. Ciğeroğlu, H. N. Ögüven, Nonlinear vibration analysis of bladed disks with dry friction dampers, Journal of Sound and Vibration 295 (2006) $1028-1043$.

[33] E. Chatelet, G. Michon, L. Manin, G. Jacquet, Stick/slip phenomena in dynamics: Choice of contact model. numerical predictions \& experiments, Mechanism and Machine Theory 43 (2008) 1211-1224.

[34] G. Michon, L. Manin, R. Dufour, Hysteretic behavior of a belt tensioner: Modeling and experimental investigation, Journal of Vibration and Control 11 (2005) 1147-1158.

[35] B. Al Sayed, E. Chatelet, S. Baguet, G. Jacquet-Richardet, Dissipated energy and boundary condition effects associated to dry friction on the dynamics of vibrating structures, Mechanism and Machine Theory 46 (2011) $479-491$.

[36] S. Le Lez, M. Arghir, J. Frêne, Nonlinear numerical prediction of gas foil bearing stability and unbalanced response, Journal of Engineering for Gas Turbines and Power 131 (2008) 012503-012503-12. 
[37] I. Iordanoff, B. Bou-Said, A. Mezianne, Y. Berthier, Effect of internal friction in the dynamic behavior of aerodynamic foil bearings, Tribology International 41 (2008) $387-395$.

[38] B. Bou-Said, G. Grau, I. Iordanoff, On nonlinear rotor dynamic effects of aerodynamic bearings with simple flexible rotors, Journal of Engineering for Gas Turbines and Power 130 (2007) 012503-012503-9.

[39] F. Balducchi, M. Arghir, R. Gauthier, Experimental analysis of the unbalance response of rigid rotors supported on aerodynamic foil bearings, Journal of Vibration and Acoustics 137 (2015) 061014-061014.

[40] L. S. Andrés, T. H. Kim, Forced nonlinear response of gas foil bearing supported rotors, Tribology International 41 (2008) 704-715.

[41] A. Al Majid, R. Dufour, Formulation of a hysteretic restoring force model. application to vibration isolation, Nonlinear Dynamics 27 (2002) 69-85.

[42] A. Al Majid, R. Dufour, Harmonic response of a structure mounted on an isolator modelled with a hysteretic operator: experiments and prediction, Journal of Sound and Vibration 277 (2004) 391-403.

[43] D. E. Brewe, B. J. Hamrock, Simplified solution for elliptical-contact deformation between two elastic solids, Journal of Lubrication Technology 99 (1977) 485-487.

[44] E. Krämer, Rolling-element Bearings, Springer Berlin Heidelberg, 1993.

[45] T. A. Harris, Rolling Bearing Analysis, John Wiley \& Sons, 2001.

[46] J. Sopanen, A. Mikkola, Dynamic model of a deep-groove ball bearing including localized and distributed defects. part 1: Theory, Proceedings of the Institution of Mechanical Engineers, Part K: Journal of Multi-body Dynamics 217 (2003) 201-211. 
[47] P. Guay, Roulements calculs (rolling-element bearings calculations), Techniques de l'ingénieur Guidage mécanique base documentaire : TIB183DUO. (2013).

[48] P. Dietl, J. Wensing, G. C. V. Nijen, Rolling bearing damping for dynamic analysis of multi-body systems: experimental and theoretical results, Proceedings of the Institution of Mechanical Engineers, Part K: Journal of Multi-body Dynamics 214 (2000) 33-43.

[49] M. Lalanne, G. Ferraris, Rotordynamics Prediction in Engineering, John Wiley \& Sons, 1998. 